\title{
Coenzyme Q10 in Heart and Brain Diseases
}

\author{
Jan Fedacko ${ }^{1, *}$, Daniel Pella ${ }^{1}$, Petra Fedackova ${ }^{1}$, Viola Vargova ${ }^{1}$, Fabien De Meester $^{2}$, \\ Petra Durcikova ${ }^{3}$ and Ram B. Singh ${ }^{4}$
}

${ }^{I} 3^{\text {rd }}$ Department of Internal Medicine, Faculty of Medicine, P.J. Safarik University, Kosice, Slovakia

${ }^{2}$ Columbus Paradigm Institute, Waterloo, Belgium

${ }^{3}$ Faculty of Medicine, Safaric University, Kosice, Slovakia.

${ }^{4}$ Halberg Hospital and Research Institute, Moradabad, India

\begin{abstract}
Background: Several cardiovascular, neurological and other diseases are associated with coenzyme Q10( CoQ) deficiency. The objective is to evaluate possible benefits of ubiquinone supplementation in cardiovascular diseases and degenerative diseases of the brain.
\end{abstract}

Methods: An internet search in PubMed, Vitasearch, In Circulation. Net, till 2008, discussions with colleagues, own experiences.

Results: Ubiquinone (Coenzyme Q10) deficiency has been observed in several cardiovascular and neurological diseases. CoQ10 has strong influence on lipid metabolism, oxidation of blood lipids, vascular inflammation and on the cell membranes of cardiac and arterial cells and neurons. These pathogenetic mechanisms seem to be important in patients with neurological and cardiac disease as well as in brain-heart connection. Its supplementation has several beneficial effects including the stabilisation of atherosclerotic plaque and decreasing the size of myoacardial infarction and the protection of neurons. Antioxidant properties of CoQ10 are responsible for the prevention of many drug side effects. Several studies have suggested the beneficial effect of CoQ10 in neuro-cardiovascular diseases, that will require further confirmation. Adverse effects such as nausea and vomiting may be reduced by using highly bio-available brands, that reduce the oral dosage of COQ.

Conclusions: CoQ10 is still in the investigational stages and the list of possible indications related to brain and heart diseases and their linkage, appears to be quite extensive. There is still the need for a number of large, double blind multicenter, randomized, controlled clinical trials, in order to confirm the possible beneficial effects of CoQ10 supplementation in different neurocardiological conditions.

Keywords: Coenzyme Q10, heart diseases, brain degeneration diseases, antioxidant, bioenergetic.

\section{INTRODUCTION}

Coenzyme Q10 was first identified by Moor et al. in 1940.Festenstein et al. in 1955 named the substance ubiquinone while Crane et al. in 1957 choose the name coenzyme Q. In 1957, Crane et al. demonstrated that it has an important role as a redox carrier in the mammalian respiratory transport chain [1]. Folkers determined the chemical formula of CoQ10 whereas Yamamura and his group were the first to use CoQ10 for the treatment of cardiovascular disease (CVD) in the 1960's. In 1972, Littarru, of Italy and the late Prof. Folkers from Texas, documented a deficiency of CoQ10 in human heart disease particularly among patients subjected to bypass surgery in Houston, USA. Stocker and coworkers as well as Singh et al. demonstrated for the first time that CoQ10 can inhibit atherosclerosis and modulate the

*Address correspondence to this author at the Center of Preventive and Sports Medicine, Medical Faculty of Safarik University and L. Pasteur Univeristy Hospital, Tr. SNP 1, 04001 Kosice, SLovakia; Tel/Fax: 00-42155-640-3861; E-mail: janfedacko@ hotmail.Com quality and chemical composition of atheroma [1-6]. Singh also observed that CoQ supplementation could be beneficial in patients with motor neuron disease, chronic renal failure and tuberous sclerosis as well as it can decrease lipoprotein(a), plasma insulin and interleukin-6.Recently, Littarru and coworkers demonstrated a beneficial effect of coenzyme Q10 on endothelial function in patients with coronary artery disease.

Coenzyme Q10 is a natural content in our diet. It is also synthesized in all body cells especially muscles. The biosynthesis of ubiquinone from the amino acid tyrosine is a multistage process requiring at least eight vitamins and several phytochemicals [1-4]. It is possible that deficiency of any of these micronutrients may result into ubiquinone deficit. CoQ deficiency of the neurons, cardiomyocytes and arterial cells can interact in predisposing circadian rhythm of cardiovascular events by stimulating suprachiasmatic nucleus, pituitary function and melatonin release from the pineal gland present in the brain [1-10]. 


\section{Biochemistry and Physiology of Ubiquinone}

There are three major steps in the biosynthesis of ubiquinone; synthesis of the ring structure from the essential amino acids tyrosine and phenylalanine, formation of the isoprenoid side chain from acetyl-CoA residues via the mevalonate pathway, and finally condensation of these structures by means of enzyme polyprenyl-transferase, possibly in Golgi apparatus. It is also possible that one essential step regulating the synthesis seems to be the hydroxymethylglutaryl (HMG)-coenzyme A reductase reaction, common with a step in cholesterol synthesis, but other steps may also be regulated. Ubiquinone has a strong influence on at least three mitochondrial enzymes (complexes I, II and III) as well as enzymes in other parts of the cell [2]. These enzymes are involved in the oxidative phosphorylation pathway and thus, are essential for the synthesis of ATP which is required for cell function [2, 3]. It may be useful in preventing cellular damage during myocardial ischemia and reperfusion. CoQ10 may prevent the oxidation of LDL cholesterol and inhibit atherosclerosis and disruption of plaque.

Its clinical benefits are mainly due to its ability to improve ATP production, antioxidant activity and membrane stabilizing properties [1-4]. These effects are beneficial in the prevention and treatment of heart disease. The antioxidant activity confers protection against lipid peroxidation and works together with vitamin $\mathrm{E}$ in prevention of damage to lipid membranes and plasma lipids [5]. Ubiquinone may offer significant protection against atherosclerosis by activating smooth muscle cells in which it is rich, and by preventing lipid peroxide formation and oxidation of low density lipoprotein cholesterol $[6,8]$. It might have some ability to maintain the integrity of myocardial calcium ion channels, sodium channels and potassium channels during ischemic insults. Ubiquinone might therefore activate potassium channels similar to nicorandil and modulate calcium channels resulting into decreased cellular calcium and improved cellular integrity during ischemia [9-11]. Reduction in cytoplasmic calcium may be associated with hyperpolarization of cell membrane which may mediate vasorelaxation and re- duce the cell damage. There is evidence that free radicals play an important role in cell damage that occurs during myocardial ischemia and reperfusion, inflammatory reactions, and in chronic neurological problems $[3,12,13]$. Free radicals are molecules containing an unpaired electron in the outer orbit rendering it chemically active. If a free radical reacts with a non-radical species, another free radical is produced. This property of self-perpetuation enables free radicals to initiate and perpetuate chain reactions. Super oxide anion $(\mathrm{O} 2)$, hydroxyl radical, hydrogen peroxide and nitric oxide are major species of free radicals which are produced during ischemia and inflammation [10,11], (Table 1).

Oxygen is the major source of free radicals during myocardial ischemia. ATP is catabolized to adenosine, inosine and hypoxanthine, which are oxidants. In addition, xanthine dehydrogenase is selectively converted into xanthine oxidase via limited proteolysis or by oxidation of the thiol groups. Oxygen combines with hypoxanthine, in the presence of xanthine oxidase reperfusion, which generates superoxide anion and another free radicals. Neutrophil is another potential source of free radicals due to the activation of NADPH oxidase [2]. This enzyme system produces superoxide radicals while mitochondria is the third source of free radicals during myocardial ischemia and inflammation. Experimental studies indicate that electrons may leak out of the mitochondrion via pathways involving NADH dehydrogenase and ubisemiquinone to produce superoxide radical. Lipid peroxidase and hydroperoxidase, present in the cell membrane lipids, are activated during ischemia that in turn release the arachidonic acid. Arachidonate in turn, accelerates the production and perpetuation of free radicals due to the action of cycloxygenase and lipooxygenase. The release of free iron and copper during ischemia also results in the production of the hydroxyl radicals $[1,4]$. These multiple mechanisms involved in the production of free radicals can result in damage to the cell membrane. As a result, there may occur a handling of calcium gradients, activation of the calcium dependent phospholipases, protein kinases, contractile elements and accumulation of mitochondrial calcium leading to further

Table 1. Possible Mechanisms of Action of coq10

\begin{tabular}{|l|l|}
\hline 1. & Repletion of CoQ10 deficiency. \\
\hline 2. & Antioxidant activity. \\
\hline 3. & Spares Vitamin E. \\
\hline 4. & Direct free radical scavenger via semiquinone species. \\
\hline 5. & Membrane stabilizing effect due to phospholipid protein interaction. \\
\hline 6. & Preservation of myocardial Na-K-ATPase activity and ATP manufacturing. \\
\hline 7. & Correction of mitochondrial "leak" of electrons during oxidative respiration. \\
\hline 8. & Induction of DT diaphorase which is an inhibitor of free radicals. \\
\hline 9. & Beneficial effect on prostaglandin metabolism. \\
\hline 10. & Inhibition of intracellular phospholipases. \\
\hline 11. & Stabilization of integrity of calcium ion dependent slow channels and possibly potassium channels. \\
\hline 12. & Spares vitamin C, A and beta carotene by decreasing their cell consumption. \\
\hline
\end{tabular}


cellular damage and necrosis. There is evidence that treatment with endogenous free radical scavengers such as superoxide dismutase and catalase can enhance cardiac function during ischemia $[1,2]$.

Ubiquinone protects the ischemic tissue from reperfusion damage by its antioxidant membrane stabilizing property and free radical scavenging activity. Furthermore, ubiquinone provides protection to myocardium by preventing the oxidation of the low density lipoprotein cholesterol. These actions provide the rationale for the experimental and clinical use of ubiquinone in the coronary artery disease, diabetes, hypertension, stroke, diabetes, neurological problems, cancer, fertility, parodontal diseases and in some diseases of unknown etiology [1-3]. These actions are similar to the ACEinhibitors and potassium channel activators. It is possible that there is an "in vivo" reduction of CoQ4 resulting in the reduced Quinol form. This short, side chain Quinol might act as a radical scavenging antioxidant by donating phenolic hydrogen to peroxyl radicals $[1,2]$.Futher possible antioxidant action may be in the capacity of ubiquinols to reduce the alphatocopheryl radical, thus allowing the regeneration of the active form of vitamin $\mathrm{E}$.

\section{Sources}

CoQ is present in the plant and animal cells and it is the most abundant form in humans and most mammals. Q9 is the primary form found in rats and mice. Q6, Q7, and Q8 are rich in the yeast and bacteria. Ubiquinone is present in all tissues but it is rich in the heart and skeletal muscles, liver and kidneys and the lowest levels are found in the lungs. Most important form of ubiquinone is its reduced form except in the brain and lung tissues. The amount of ubiquinone in the human plasma ranges between 0.75 to $1.0 \mathrm{Ug} / \mathrm{ml}$ of which $75 \%$ is in the reduced form. The total content of ubiquinone in the body has been estimated at 1.0-1.5 g, most of which is found in the muscle cells. Ageing may be associated with the decrease in ubiquinone levels. Ubiquinone levels may be increased by biosynthesis, from food and through supplements. Exercise also enhances the biosynthesis of ubiquinone in the body. Pork heart, fish, vegetables, particularly cauliflower, soya bean and sweet potato are good sources of ubiquinone. Based on the food frequency studies in 1985 and 1995 by the National Food Agency of Denmark, the dietary intake of ubiquinone was estimated to be 3-5 $\mathrm{mg} /$ day in Denmark [5]. In Indians the dietary intakes may be $2-3 \mathrm{mg} / \mathrm{day}$. The recommended daily intake has not yet been determined. It is possible that an intake of $10-30 \mathrm{mg} /$ day is enough for healthy individuals. The plasma levels of ubiquinone is lower in South Asians compared to Caucasians and Chinese.

\section{ABSORPTION AND EXCRETION OF COENZYME Q10}

Ubiquinone is slowly absorbed from the gastrointestinal tract because it is soluble in lipids. The mean plasma level after a single $100 \mathrm{mg}$ oral dose of ubiquinone in human subjects is $1.004+0.37 \mathrm{ug} / \mathrm{ml}[1,2]$. The mean steady state level after three daily administrations of $100 \mathrm{mg}$ has been estimated to be $5.4 \mathrm{ug} / \mathrm{ml}$. A softsule developed by Tishcon Corporation (USA) is hydrosoluble and may provide better serum levels with relatively lower dosages. . It has a relative long plasma half life of $33.9+5.32$ hours, indicating a low clearance rate from the plasma. A large portion of the exogenous dose of ubiquinone is deposited in the liver and packaged into very low density lipoprotein. The excretion is via the biliary tract and approximately $62.5 \%$ of the drug may be recovered in the stools. During chronic administration, the drug is concentrated in adrenal, spleen, lung, kidney, liver, brain and myocardial tissue.

\section{DEFICIENCY OF COENZYME Q10}

Ubiquinone deficiency [1-6] may be due to insufficient dietary intake, impairment in CoQ10 biosynthesis, excessive utilization by the body or a combination of any three [1-4]. There is an increased requirement of CoQ10 by body tissues due to their consumption by the cells in several diseases such as coronary artery disease particularly with angina pectoris, congestive heart failure, mitral valve prolapse, etc. (Table 2). It is possible that poor body stores or low dietary intake can predispose several of the diseases mentioned in the Table $\mathbf{2}$ and ubiquinone supplementation may have beneficial effects. Environmental oxidants such as pollutants, pesticides, heavy metals, industrial fumes, radiation and increased consumption of linoleic acid may enhance oxidative stress in the tissues and may enhance the requirement of ubiquinone. Decreased synthesis and poor supply may cause ubiquinone deficiency. The plasma level of ubiquinone is approximately two-fold higher among vegetarians than in omnivores, indicating that a high intake of these foods may also provide high CoQ10 levels (0.86 vs. $0.44 \mathrm{ug} / \mathrm{ml})$ [1-4].

\section{CLINICAL USES OF COENZYME Q10}

Ubiquinone deficiency in various clinical conditions and experimental observation of myocardial protection during ischemia [13] by ubiquinone, reasonably constitutes one of the sound reasons for the therapeutic use of ubiquinone in human heart disease, diabetes, myopathy, Huntington's disease, Parkinson's disease. Indications for ubiquinone administration are growing gradually. There is also the need to include mitochondrial diseases, drug interactions (eg. statins) and a meaningful discussion of the poor bioavailability issues surrounding the oral administration of CoQ10 [14].

\section{CORONARY ARTERY DISEASE}

Hiasa [15] performed the first controlled trial with ubiquinone, specifically in patients with angina. Ubiquinone group showed a prolongation in exercise time with 8 to 12 patients. This showed an increase of one stage or more on a modified Bruce protocol and no increase in exercise duration in the placebo group. Treatment with ubiquinone decreased ST segment depression without any influence on heart rate, blood pressure or double product. It is noteworthy that five controlled trials from 1984-1991 showed rapid and marked improvement in the symptoms of angina as well as a reduction in the degree of ischemic ST segment depression with exercise stress testing with no change in hemodynamics (Table 3). In one clinical study by Kamikawa et al. [16] oral ubiquinone (150 mg/day) or placebo were given for 4 weeks in 12 patients with chronic stable angina. This was followed by a crossover to the opposing treatment regimen for another 4 weeks. Exercise time and time to $1 \mathrm{~mm}$ electrocardio- 
Table 2. Diseases Associated with CoQ10 Deficiency

\begin{tabular}{|c|c|}
\hline Non-cardiovascular Conditions & Cardiovascular Diseases \\
\hline $\begin{array}{l}\text { 1. Persistent nausea, vomiting and diarrhea } \\
\text { 2. Cachexia } \\
\text { 3. Chronic malnutrition } \\
\text { 4. Suboptimal dietary intake of CoQ10 } \\
\text { 5. Aging } \\
\text { 6. Obesity } \\
\text { 7. Acute shock states } \\
\text { 8. Diabetes mellitus } \\
\text { 9. Cancer } \\
\text { 10. Immune deficiency } \\
\text { 11. Peridontal disease } \\
\text { 12. Muscular dystrophy } \\
\text { 13. Drug therapy eg. statins, adriamycin, diuretics (possible) } \\
\text { 14. Excessive exertion } \\
\text { 15. Hypermetabolism } \\
\text { 16. Huntington's disease. } \\
\text { 17. Parkinson's disease. } \\
\text { 18. Motor neuron disease. } \\
\text { 19. Tuberous sclerosis. ? }\end{array}$ & $\begin{array}{l}\text { 1. Angina pectoris } \\
\text { 2. Coronary artery disease } \\
\text { 3. Congestive heart failure } \\
\text { 4. Hypertension } \\
\text { 5. Cardiomyopathy } \\
\text { 6. Mitral valve prolapse } \\
\text { 7. Revascularization } \\
\text { 8. Stroke }\end{array}$ \\
\hline
\end{tabular}

Table 3. Clinical Controlled Studies on Coq10 in Chronic Stable Angina

\begin{tabular}{|l|l|l|l|}
\hline Author & n & CoQ10, Daily Dose & Significant Findings \\
\hline \hline Hiasa (1984) & 18 & $1.5 \mathrm{mg} / \mathrm{kg}$ i. v. & Increased exercise tolerance, less angina \\
\hline Kamikawa (1985) & 12 & $150 \mathrm{mg}$, oral & Improved exercise tolerance, longer time to ST depression \\
\hline Schardt (1986) & 15 & $600 \mathrm{mg}$, oral & Less ST depression \\
\hline Wilson (1991) & 58 & $300 \mathrm{mg}$, oral & Improved exercise tolerance, longer time to angina \\
\hline Serra (1991) & 20 & $60 \mathrm{mg}$, oral & Improved cardiac output, less angina, less nitrate use \\
\hline
\end{tabular}

graphic ST-depression were significantly increased in the ubiquinone group compared to placebo group. Schardt et al. [17] compared the effect of $600 \mathrm{mg} /$ day of oral CoQ10 with placebo and the combination of pindolol $(7.5 \mathrm{mg} /$ day $)$ and isosorbide dinitrate $(30 \mathrm{mg} /$ day) in 15 patients with chronic stable angina. Treatment with ubiquinone was associated with a significant reduction in cumulative exercise induced ST-segment depression compared to placebo. Ubiquinone in doses of 150 or $300 \mathrm{mg} /$ day was compared with placebo in 37 patients on exercise duration in stable angina at 10 different centers. CoQ10 monotherapy caused an increase in exercise duration to onset of angina of 70 seconds in the $300 \mathrm{mg}$ group and 65 in the $150 \mathrm{mg}$ group at end of first week; 140 and 127 seconds respectively by week 4 .There was a $60 \%$ decrease in the frequency of anginal attacks in the $150 \mathrm{mg}$ group.

In post infarction patients, [19] treatments with CoQ10 caused a significant beneficial effect on work capacity and significantly lower level of malondialdehyde in the treatment group compared to placebo. In one 58 year old patient with diabetes mellitus and refractory unstable angina, the addition of ubiquinone $(60 \mathrm{mg} /$ day $)$ to treatment with nitrates and calcium blockers was associated with exercise tolerance and relief in angina within 2 weeks; no response was observed during the last 4 weeks with conventional drugs [3-5].

\section{CONGESTIVE HEART FAILURE}

Since oxidative stress, mitochondrial dysfunction and energy starvation in conjunction with neurohormonal dysfunction are the basic mechanisms in heart failure, it is possible that the heart failure may be the main indication for treatment with ubiquinone (Table 4) [18-35]. Most clinical trials with ubiquinone focus on heart disease due to the known high ubiquinone content of the myocardium and to the high amount of energy required for normal heart function. After the publication of pioneering Japanese studies in 
Table 4. Controlled Trials of Coq10 in Heart Failure

\begin{tabular}{|c|c|c|c|c|}
\hline Author & No. of Patients & Diagnosis & CoQ10 Daily Oral Dose & Significant Findings \\
\hline Hashiba (1972) & 197 & $\mathrm{CHF}$ & $30 \mathrm{mg}$ & Imp. NYHA class \\
\hline Iwabuchi (1972) & 38 & $\mathrm{CHF}$ & $30 \mathrm{mg}$ & Imp. NYHA class \\
\hline Langsjoen (1985) & 19 & $\mathrm{CHF}$ & $100 \mathrm{mg}$ & Increased EF \\
\hline Vanfrachem (1986) & 15 & CHF & $100 \mathrm{mg}$ & Imp. Co. EF. SV Aerobic capacity \\
\hline Judy (1986) & 14 & $\mathrm{CHF}$ & $100 \mathrm{mg}$ & Imp. Co. \& EF \\
\hline Schneeberger (1986) & 12 & $\mathrm{CHF}$ & $100 \mathrm{mg}$ & Imp. Co. \& EF \\
\hline Oda (1990) & 40 & MVP with DD & $3 \mathrm{mg} / \mathrm{kg}$ & Imp. DF \\
\hline Rossi (1991) & 20 & ICM & $200 \mathrm{mg}$ & Imp. Exercise tol. \\
\hline Poggesi (1991) & 20 & ICM \& IDCM & $100 \mathrm{mg}$ & Imp. EF \\
\hline Judy (1991) & 180 & $\mathrm{CHF}$ & $100 \mathrm{mg}$ & Imp. 8 yr. survival \\
\hline Permanetter (1992) & 25 & IDCM & $100 \mathrm{mg}$ & No benefits \\
\hline Rengo (1993) & 60 & $\mathrm{CHF}$ & $100 \mathrm{mg}$ & Imp. EF Imp. NYHA class \\
\hline Morisco (1993) & 641 & $\mathrm{CHF}$ & $2 \mathrm{mg} / \mathrm{kg}$ & Less hosp. for CHF at $1 \mathrm{yr}$ \\
\hline Morisco (1994) & 6 & $\mathrm{CHF}$ & $150 \mathrm{mg}$ & Imp. EF SV Co. by MUGA scan \\
\hline Hofman-bang (1995) & 79 & CHF & $100 \mathrm{mg}$ & Imp. Vol. load EF \\
\hline Watson et al. (1999) & & $\mathrm{CHF}$ & $200 \mathrm{mg}$ & No effect \\
\hline Khatta et al. (2000) & 55 & $\mathrm{CHF}$ & $200 \mathrm{mg}$ & EF, no effect \\
\hline Singh RB (unpublished) & 42 & $\mathrm{CHF}$ & $120 \mathrm{mg}$ & Imp. NYHA class, EF \\
\hline
\end{tabular}

Abbreviations: Imp. , improved; LV, left ventricular; EF, ejection fraction; CO, cardiac output; SV, stroke volume; CHF, congestive heart failure unspecified etiology; MVP, mitral valve prolapse; DD, diastolic dysfunction; ICMN ischemic cardiomyopathy; IDCM, idiopathic dilated cardiomyopathy; hosps. , hospitalizations; vol. , volume.

the late 1960's and early 1970's, there have been 15 randomized controlled trials involving 1366 patients with various causes of heart failure. Our randomized controlled trial in 42 patients increased this number to 1408 subjects in which CoQ10 was administered for the treatment of heart failure. In Japan, about 48 controlled and open trials have been conducted to study the role of CoQ10 in heart failure [29]. In the early trials, beneficial effects in the manifestations of heart failure were observed with smaller doses of $30 \mathrm{mg}$ ubiquinone per day. However, rapid recovery from heart failure was noted using up to $200 \mathrm{mg} /$ day of CoQ10 in later studies when more attention was paid to the therapeutic levels of the drug.

Serum level of CoQ10 $>1.0 \mathrm{ug} / \mathrm{ml}$ is usually associated with optimal improvement in heart function and this level is considered as normal. CoQ10 deficiency is considered when the level is $<0.5 \mathrm{ug} / \mathrm{ml}$ and the therapeutic level, when it is $>2.5 \mathrm{ug} / \mathrm{ml}$. The requirement for a supraphysiological level of ubiquinone is not clear but high blood CoQ10 level may be required to attain adequate tissue levels. It is possible that more data on blood and myocardial tissue levels of ubiquinone would be necessary to explain this question.

Mortensen and Folkers [21] reported that patients in NYHA classes III and IV showed diminished contents of cardiac CoQ10 when compared to the patients in class 1 and
2. It is possible that there may be an impairment in the CoQ10 biosynthesis, accelerated catabolism, or a combination of both which caused a deficiency. Increased antioxidant commitment of ubiquinone may somehow lead to accelerated consumption leading to deficiency. It is possible that exogenous CoQ10 administration may increase the velocity of electron transfer, especially when endogenous pool is diminished as in cases of higher levels of lipid peroxidation. In one study [19] involving 79 patients of heart failure in a double blind crossover trial, the intervention group showed improvement in physical performance and exercise capacity consistent with captopril-digoxin multicenter research trial. In another double blind trial [20] involving 33 centers and comprising 641 patients, 319 were administered ubiquinone and 322 placebo for 12 months. Although the mortality (16 vs 21) was not significantly lower, the incidence of acute pulmonary oedema, arrhythmias, hospitalizations and incidence of class III and IV heart failure was significantly lower in the CoQ10 group. Clinical benefit score 1.4 was much higher in the treatment group. In another double blind and controlled study [18] by Ursini et al. (Paciarioni group), the treatment with CoQ10 was associated with significant reduction of catecholamine levels indicating that ubiquinone can modulate neurohormonal dysfunction which is the basis in heart failure. 
There was also a clinical improvement in the intervention group compared to the control group in a group of elderly heart failure patients. However, a German double blind study [22], showed no benefit of CoQ10 in patients with wellpreserved cardiac function. In a long-term randomized survival study among 90 class IV congestive heart failure patients by Judy et al. [23], treatment with 100mg/day of CoQ10 showed significant benefit compared to control group during a follow-up of 8 years.

In congestive heart failure due to CAD, there may be an ischemia-reperfusion induced free radical stress in conjunction with higher serum catecholamines [30], insulin and angiotensin converting enzyme with a rise in atrial natriuretic peptide and brain-natriuretic peptide. Higher sympathetic activity and catecholamines, as well as angiotensin II in heart failure, may be associated with a deficiency of endogenous antioxidants such as catalase and super-oxid-dismutase, glutathione as well as antioxidant vitamins $\mathrm{A}, \mathrm{E}$ and $\mathrm{C}$ and betacarotene and CoQ10 which further enhance the oxidative stress. These biochemical abnormalities may cause the deterioration of the heart failure. In experimental animals, an improved myocardial redox state with long-term antioxidant therapy has been shown to modulate the development and progression of heart failure. This study provides further proof to the rationale regarding the use of antioxidants in heart failure. Carvedilol, an antioxidant and betablocker, has also been found to retard heart failure indicating that a decrease in oxidative stress and sympathetic activity may be of benefit in heart failure [30]. Ubiquinone has also been successfully used in patients with refractory heart failure [31]. In one metaanalysis of randomized trials [32], published between 1984-1994, only 8 out of 14 studies met the inclusion criteria. These studies comprised a total of 356 patients.

Treatment with CoQ10 was consistent with improvement in stroke volume, ejection fraction, cardiac output, cardiac index and end diastolic volume index compared to control group. However, a few studies [33, 34] showed no benefit of CoQ10 in congestive heart failure, mainly due to lack of sufficient rise in plasma levels of ubiquinone.

\section{CARDIOMYOPATHY}

Ubiquinone deficiency is the cause or effect of cardiomyopathy (CMP) has not yet been proven $[36,37]$. In one study, tissue levels of ubiquinone were significantly lower among NYHA class IV subjects of CMP compared to class 1 and 2 subjects [4]. The greater the deficiency of ubiquinone, the better the response to treatment with ubiquinone, indicating CMP. Significant improvement was noted in patients with dilated CMP with class III and IV heart failure in a randomized double blind study when they were administered CoQ10 [38, 39]. In other studies of patients with CMP, coenzyme $Q$ treatment showed adequate benefits [18-21]. There is extensive evidence from in vitro and animal experiments that CMP is a state of increased oxidative stress. Coenzyme Q10 (CoQ10) and high-sensitivity C-reactive protein (hs-CRP) are important markers to evaluate the oxidative stress and inflammatory status of patients with CMP. In this study os Senes, evidence of decreased antioxidant status was determined in CMP patients together with vascular inflammation. CoQ10, other plasma antioxidants and hsCRP measured routinely can reflect decreased antioxidant status and inflammatory process in patients with dilated CMP. These markers can be used to monitor the status of patients with CMP [40].

\section{Myocardial Preservation and Intervention}

There is evidence that prior ubiquinone therapy provides protection against ischemic reperfusion [1-4], (Table 5). In a rabbit heart model of ischemia and reperfusion, a role of CoQ10 in preserving ischemic myocardium was observed. Myocardium, pretreated with ubiquinone, was relatively protected against both structural and functional changes induced by ischemia and reperfusion. The animals pretreated with CoQ10 were able to maintain oxidative phosphorylation and cellular ATP generating capacity and showed that cellular and mitochondrial calcium overload was prevented by pretreatment with ubiquinone. The clinical and metabolic beneficial effects were similar in magnitude to those seen with propranolol and verapamil [1]. CoQ10 has been demonstrated to protect both $\mathrm{Ca}$ dependent and $\mathrm{Na}-\mathrm{K}$ dependent ATPase activity. The effectiveness of ubiquinone in preventing low cardiac output states following cardiac surgery was compared in a randomized study in humans. Judy et al. [26] demonstrated myocardial preservation by prior treatment CoQ10 for 15 days before heart surgery and compared with 30 days treatment after the surgery. The CoQ10 group showed optimal blood and tissue CoQ10 and tissue ATP

Table 5. Controlled Trials of Coq10 in Cariac Surgery

\begin{tabular}{|l|l|l|l|}
\hline Author & No. of Patients & CoQ10 Daily Dose & Significant Postoperative Findings \\
\hline \hline Tanaka (1982) & 50 & $30-60 \mathrm{mg}$ p. o. 6 days preop & Imp. Co \\
\hline Sunamori (1991) & 78 & $5 \mathrm{mg} / \mathrm{kg}$, i. e. 2 hrs preop 14 days preop & $\begin{array}{l}\text { Imp. LV stroke work index, decreased CPK - MB Imp. } \\
\text { LV ejection fraction, shortened recovery time }\end{array}$ \\
\hline Judy (1993) & 20 & $100 \mathrm{mg}, 14$ day, preop & EF improv, recovery time less \\
\hline Chello (1994) & 40 & $\begin{array}{l}150 \mathrm{mg} \text { p. o. } \\
7 \text { days preop. }\end{array}$ & $\begin{array}{l}\text { Decreased markers of oxidative damage } \\
\text { Less arrhythmia, less need for inotropes }\end{array}$ \\
\hline Chen (1994) & 22 & $150-200 \mathrm{~kg}$, p. o. $5-7$ days preop. & Increased pulse pressure Imp. LV ultrastructure \\
\hline Taggart (1994) & 20 & $600 \mathrm{mg} \mathrm{p.} \mathrm{o.} \mathrm{12} \mathrm{hrs,} \mathrm{preop.}$ & No benefit \\
\hline
\end{tabular}

Abbreviations: No. = number of; p. o. = per os; ejection fraction; $\mathrm{CO}=$ cardiac output; Imp. = improved; preop. = preoperatively; LV = left ventricular. 
levels, improvement in cardiac pumping and ejection fraction, as well as an uncomplicated and short recovery period compared to placebo group.

\section{Cardiac Arrhythmias}

In experimental coronary artery ischemia, pretreatment with ubiquinone increased the ventricular fibrillation threshold while minimizing the impairment in contractility and myocardial stunning [41]. The antiarrhythmic effect of CoQ10 has been studied in several experiments. Treatment with CoQ10 was associated with prolongation of action potential duration in right ventricular papillary muscles. Clinical studies on the role of CoQ10 in patients with ventricular ectopic activity indicate that $20-25 \%$ of patients respond to treatment with this agent $[1,2]$. These studies also showed a consistent effect of CoQ in shortening the QT interval, including QTc. CoQ10 may have similar effect on QT interval in patients receiving psychotropic agents. It seems that CoQ10 prevents the stimulation of excitable tissues in the heart as well as in the brain. Therefore treatment with CoQ10, similar to n-3 fatty acids might modulate the acute precipitating trigger that lies in the excitable tissue of brain and the chronic electrical instability of the myocardium, contributing to prevention of sudden cardiac death.

\section{HYPERTENSION}

There are not very many studies on the role of CoQ10 in hypertension [42-44]. In earlier studies, Yamagami et al. used CoQ10 in 29 patients with hypertension with some success. In a randomized double blind trial on 59 patients receiving antihypertensive drugs, the effects of oral treatment with CoQ10 (60mg twice daily) were compared for 8 weeks in 30 intervention group and 29 control group patients known to have hypertension and presenting with acute CAD [44]. After 8 weeks of follow-up, the following indices were reduced in the CoQ10 group: systolic and diastolic blood pressure, fasting and 2-h plasma insulin, glucose, triglycerides, lipid peroxides, malondialdehyde and diene conjugates. The following indices were increased; HDL cholesterol, vitamins $\mathrm{A}, \mathrm{C}, \mathrm{E}$ and beta-carotene $(\mathrm{P}<0.05)$. These findings indicate that treatment with CoQ10 decreases blood pressure possibly by decreasing oxidative stress and insulin response in patients with known hypertension receiving conventional antihypertensive drugs. In a recent study by Langsjoen et al. [44] in 109 patients with known essential hypertension, CoQ10 (225 mg/day average) was administered to achieve serum level of $2 \mathrm{ug} / \mathrm{ml}$, in conjunction with anti-hypertensive drugs.

There was a need to withdraw one to three drugs in $51 \%$ of patients. The decrease in systolic blood pressure was from 159 to $147 \mathrm{mmHg}$, mean and in diastolic blood pressure from 94 to $85 \mathrm{mmHg}$. In a meta-analysis of the clinical trials CoQ10 has shown the potential in hypertensive patients to lower systolic blood pressure by up to $17 \mathrm{~mm} \mathrm{Hg}$ and diastolic blood pressure by up to $10 \mathrm{~mm} \mathrm{Hg}$ without significant side effects [45]. A further study [18], showed that CoQ10 causes a significant decrease in serum catecholamines and possibly reduces peripheral vascular resistance. The available data indicate that a double blind randomized study should be conducted with higher doses (100-200 mg/day) of CoQ10 with a long-term follow up.

\section{MYOCARDIAL TOXICITY OF ADRIAMYCIN}

Adriamycin, an anthracycline and mixed quinoid and hydroquinoid compound may have inhibition effects on CoQ10 enzyme systems. Repletion with CoQ10 can prevent the inhibition of CoQ10 enzymes in mitochondrial preparations. In several other experimental studies, the role of exogenous CoQ10 in preventing adriamycin toxicity was corroborated [1]. Clinical studies also showed beneficial effects on systolic time intervals of pretreatment with CoQ10 (a manifestation of adriamycin toxicity) in cancer patients. In a randomized [32] and controlled study on 20 patients with cancer, 10 were supplemented with $200 \mathrm{mg} /$ day of CoQ10 for the duration of treatment with anthracyclins [46]. Echocardiographic monitoring showed protective effects on the left ventricular contractile function in the form of less decrease in ejection fraction and of shortening fraction in the CoQ10 group compared to control subjects. It is possible that CoQ10 therapy causes repletion of a CoQ10 deficiency induced by adriamycin and inhibits adriamycin induced lipid peroxidation and free radical generation.

\section{PLASMA LIPOPROTEINS}

In one in vitro experiment [6], it has been demonstrated that following exposure to free radical source (Azo compounds), low density lipoproteins (LDL) deployed their antioxidant reserve which were consumed while inhibiting the oxidative attack. When LDL, depleted of ascorbic acid, was exposed to free radical source, peroxidation remained under control as long as some ubiquinol was present. The findings suggested that ubiquinone as an antioxidant may be more efficient than tocopherol and carotenoids in preventing the oxidation of LDL.

A double blind controlled study [6], in patients with hypercholesterolemia showed that treatment with HMGCOA reductase-1 (lovastatin) was associated with significantly lower plasma level of CoQ10 compared to placebo [47]. The decrease in CoQ10 appears to be due to the fact that cholesterol and CoQ10 share the same biosynthetic pathway. These findings were confirmed in a crossover trial with CoQ10 and HMGCOA inhibitors [48]. This study showed a decrease in CoQ10 in plasma, as well as in platelets which was prevented by concomitant administration of CoQ10.In one experimental study, Singh et al. [49] demonstrated that lovastatin has a modest antioxidant activity which may be similar to fluvastatin. Despite a reduction in CoQ10, induced by statins, oxidation of LDL is inhibited by the statins with no serious adverse effect of CoQ10 deficiency. However, treatment of hypercholesterolemia with HMGCOA reductase inhibitors in conjunction with CoQ10 may provide greater benefit in the regression of coronary atherosclerosis and prevention of cardiac events. We also observed in a sub study that CoQ10 treatment may be associated with significant reduction in lipoprotein level and plasma insulin levels in patients with acute coronary syndromes $[44,50]$. In a randomized, double blind, placebo controlled trial [51] in 47 patients with acute CAD and moderately raised lipoprotein(a) $\{\mathrm{Lp}(\mathrm{a})\}$, treatment with CoQ10 (60mg twice daily) in 25 interventions and 22 control group patients were given. After 28 days, serum Lp(a) level showed significant reduction in CoQ10 group compared with the placebo group $(31.0$ vs $8.2 \%, \mathrm{P}<0.001$ ) with a net reduction of $22.6 \%$ attributed 
to CoQ10.HDL cholesterol showed a significant increase in the intervention group. CoQ10 treatment was also associated with significant reductions in thiobarbituric acid reactive substances, malondialdehyde and diene conjugates indicating an overall decrease in oxidative stress.

The effects of the administration of CoQ10 (5mg/kg/day) (group $\mathrm{A}, \mathrm{n}=10$ ) and placebo (group $\mathrm{B}, \mathrm{n}=10$ ) were compared over 24 weeks in a randomized, single blind controlled trial [52]. There were two groups of rabbits receiving a trans fatty acid rich diet (5-8g/day) for 36 weeks. Oxidized rabbits chow with vitamin $\mathrm{C}$ plus ferric chloride was administered for 4 weeks in all rabbits. Intervention with CoQ10 after feeding of TFA rich diet was associated with a significant decline in thiobarbituric acid reactive substances (TBARS), diene conjugates and malondialdehyde, as well as an increase in plasma levels of vitamin $\mathrm{E}$ in the CoQ10 group compared to placebo group. The aortic and coronary artery plaque quality also showed beneficial effects which would be discussed later [53].

\section{Acute Myocardial Infarction}

A recent study has shown that CoQ10 can inhibit human vitronectin receptor expression indicating that it might inhibit thrombosis [54]. In one study by Kuklinski et al. [55], in patients with AMI, treatment with CoQ10+selenium for 6 months was associated with significant less patients with prolonged QT interval compared to control group. There were no deaths in the treatment group (0 vs 6) during a follow up of 6 months. Singh et al. [51], conducted a randomized, double blind, controlled trial in 144 patients with AMI. Treatment with CoQ10 (60 mg twice a day) was associated with significant decrease in arrhythmias, angina and cardiac enlargement in the intervention group compared to control group during the follow up of 4 weeks. Nonfatal infarction and cardiac deaths were significantly less in the CoQ10 group than control group (15 vs $31 \%, \mathrm{P}<0.02)$ [52].

\section{ATHEROSCLEROSIS AND INSTABILITY OF ATHEROMA}

CoQ10 and vitamin E can have synergic effects and CoQ deficiency may decrease the beneficial effect of vitamin B6 [56]. Littarru and coworkers [57] demonstrated a deficiency of CoQ in cardiac muscle and possibly in the arterial smooth muscle which are important in the pathogenesis of left ventricular hypertrophy $(\mathrm{LVH})$ and atherosclerosis respectively [58-62]. LVH and atherosclerosis are risk factors of acute myocardial infarction (AMI) and sudden cardiac death (SCD). It is now widely accepted that unstable atheroma and subsequent plaque rupture is a major cause of myocardial infarction and stroke [52-65]. Clinical trials with statins [49, $66,67]$ showed only minor effects on the size of existing lesions but major reduction in clinical events, despite the fact that these agents decrease $\mathrm{CoQ}$ as a side effect of drugs. These results indicate that despite statin induced CoQ deficiency, there is a beneficial effect on stability and chemical composition of atherosclerotic plaque [66]. There is a need to know that how active the plaques are, rather than just the severity of stenosis that is routinely assessed by angiography. Antioxidants such as vitamin E, C, beta carotene, minerals, selenium, zinc, copper, magnesium and calcium and lycopene, CoQ10, n-3 fatty acids, amino acids in conjunction with lipids, appear to be important determinants of the chemical composition and quality of atherosclerotic plaque [68]. While regular physical activity stabilizes the atheroma, tobacco consumption, sedentary behavior, hyperinsulinemia, hyperglycemia, hypertriglyceridemia and low high density lipoprotein (HDL) may increase the vulnerability of the plaque. Thrombosis is also the major initiating factor in unstable angina particularly when chest pain is recent and increasing in severity. However, the thrombosis in unstable angina is mainly due to white platelets which do not respond to fibrinolytic streptokinase.

\section{THE ATHEROSCLEROTIC PLAQUE}

The fully developed human fibrolipid, atherosclerotic plaque as defined by American Heart Association (Type IV or Type V) has a core of lipid surrounded by a capsule of connective tissue [63-65]. It begins as a subendothelial accumulation of lipid-laden monocyte derived foam cells and associated T-cells which form a non-stenotic fatty streak. Progression of fatty streak results into plaque having extracellular lipid cholesterol and its esters bounded by an endothelized fibrous cap containing vascular smooth muscle cell (SMC) and inflammatory cells. It predominantly macrophages with some T-cells and mast cells which tend to accumulate at the shoulder regions of the plaque $[63,64]$. In the advanced lesions, new blood vessels and deposits of calcium may be present. The macrophages may be laden with cholesterol or lipids which are called foam cells. These macrophages are derived from monocytes which crossed the endothelium from the arterial lumen. These macrophages are highly activated producing procoagulant tissue factor and a host of inflammatory cell mediators such as tumor necrosis factor, interleukins and metaloproteinases. The connective tissue capsule which surrounds above inflammatory mass is collagen synthesized by the SMCs. This portion of the capsule separating the core from the arterial lumen itself is the plaque cap which is fibrous and determines the stability of the plaque. Although recruitment of inflammatory cells is important for plaque development, they do not accumulate in the intima in the absence of lipids. Therefore lipid accumulation is the initiating event and that inflammatory cells play a permissive role in lesion progression.

\section{OXIDIZED LOW DENSITY LIPOPROTEIN CHOLESTEROL}

Oxidized LDL exhibits a variety of pro-atherogenic actions including inflammation, endothelial dysfunction, the attraction and retention of blood monocytes in the intimal space and the promotion of foam cells as well as cytotoxicity and SMC proliferation. Myeloperoxidase-derived oxidants, reactive nitrogen intermediates, oxygen centered radicals and also possibly 15 lipoxygenase, transition metal ions are important in oxidizing the LDL. However, the exact oxidants involved and the extent of molecular mechanisms of LDL oxidation in human body are yet to be studied. Therefore, apart from hypolipidemic agents, LDL antioxidants appear to be potential anti-atherosclerotic agents in the management of atherosclerosis. There is some evidence [68-70] which indicates that to be anti-atherogenic, an antioxidant needs to be associated with LDL in adequate concentrations. Human LDL contains a number of endogenous antioxidants such as alpha-tocopherol, which is higher than ubiquinol-10, gama- 
tocopherol, lycopene and carotenoids. There is also evidence that higher doses of alpha tocopherol can decrease the availability of CoQ as well as gama-tocopherol which may have adverse effects including enhanced pro-inflammatory responses in the atherosclerotic plaque. CoQ10H2 is the first antioxidant consumed in LDL exposed to various oxidants and it inhibits LDL lipid peroxidation by reducing the chain carrying alpha-tocopheroxyl radical and exporting the radical from the lipoprotein particle. Enrichment of LDL with CoQ10H2 by dietary supplementation with CoQ10 inhibits ex vivo LDL oxidation.

\section{OXIDATION OF LDL AND COENZYME Q10}

Experimental studies indicate that when LDL is exposed to oxidants, reduced CoQ10 is the first antioxidant to be consumed [8, 69-71]. Formation of oxidized lipids is markedly suppressed while reduced CoQ is present in the LDL. Fresh and rapidly isolated LDL contains comparatively smaller amount of reduced CoQ than vitamin E. Only second LDL particle contains on average, one molecule of reduced CoQ10 in non-supplemented human subjects. However, dietary supplementation with CoQ (100-300 mg/day) may cause greater concentrations of reduced $\mathrm{CoQ}$ in plasma and all of its lipoproteins [71]. A maximal concentration is achieved in LDL after 4-5 days of daily CoQ administration (from 0.50.8 normal to 2.0-3.0 CoQ10 reduced molecules per LDL). Increased concentration of reduced CoQ10 also overcomes and fully prevents the pro-oxidant effect seen with alphatocopherol supplementation. It is not clear how such small levels of reduced CoQ10 provide significant antioxidant protection against low fluxes of a variety of different oxidants. It seems that reduced CoQ10 exhibits antioxidant activity for LDL lipids by inhibiting the chain transfer activity of alphatocopheroxyl radicals [71, 72].

Experimental studies [8] reveal that scavenging of alphatocopheroxyl by reduced CoQ can explain that cosupplementation with reduced CoQ10 inhibits the prooxidant effect of supplementation with alpha-tocopherol alone. In other words, alpha-tocopherol requires coantioxidants for efficient antioxidation of LDL lipids. Increased number of reduced CoQ10 molecules per LDL particle from $<1$ to $>1$ is likely to substantially increase the resistance of the lipoprotein towards lipid peroxidation and may be crucial with respect to effecting antioxidant protection of LDL.

\section{INFLAMMATION}

The lipid laden monocytes accumulate in the subendothelial space and exacerbate the local inflammatory reaction which becomes more severe if the lipids are oxidized [6265]. Subendothelial lipids also maintain activation of the overlying endothelium resulting into continued expression of selectin and adhesion molecules and also expression of chemokines in particularly monocyte chemoattractant proteins-1 (MCP-1). Chemokines are pro-inflammatory cytokines that function in leucocyte chemoattraction and activation. The inflammatory cells once captured, migrate into the subendothelial space where they are activated by local chemokines. Activated macrophages and T cells also express a variety of pro-inflammatory cytokines and growth factors that contribute to the evolution of the plaque. It is possible that a subendothelial inflammatory stimuli and the local adaptive wound healing response of vascular smooth cells interact to form atherosclerotic plaque [64, 65]. CoQ can inhibit atheroma development by inhibiting proinflammatory agents as well as by SMC activation due to energy production in the cells.

\section{ARTERIAL SMOOTH MUSCLE CELLS}

Smooth muscle cells (SMC) gene expression of the intima in atherosclerosis and SMCs in the early developing blood vessel have many similarities indicating that intimal SMCs are likely to be performing a reparative rather than a permissive role in atherosclerosis [14]. In adopting a repair phenotype, SMCs express the proteinases that break down the basement membrane to facilitate their migration to the site of injury [72, 73]. SMCs produce growth factors which help in their proliferation at the site of injury and they also produce collagen and elastin to repair the artery [70, 71]. Expression of this repertoire of genes is essential for the formation of a fibrous cap over the lipid core of a plaque. It is clear that SMC is the only capable cell which synthesizes the cap and plays a pivotal role in maintaining plaque stability. The fibrous cap separates the highly thrombogenic lipidrich core from circulating platelets and proteins of coagulation cascade and confers structural stability to a lesion [66]. Since CoQ10 deficiency is an important factor in predisposing atherosclerosis, it is possible that SMC deficiency of CoQ10 might decrease energy production in the cells and alter their capability of forming a strong fibrous cap. It is also possible that CoQ10 supplementation would enhance the capability of SMC to form a stronger fibrous cap, as well as attenuate their proliferation to prevent atherogenesis and instability of atheroma [64, 72, 73].

\section{INTERACTIONS OF CELLS AND PLAQUE RUPTURE}

There is an accumulation of platelets leading to intravascular thrombosis if the atherosclerotic plaque ruptures or erodes resulting into acute coronary syndromes of unstable angina, and myocardial infarction [64]. The most important determinant of plaque rupture such as large lipid pool, thin fibrous cap of atheroma and preponderance of inflammatory cells produce metaloproteases and metaloproteinases, (which degrade matrix proteins and weaken the cap of plaque) and pro-inflammatory cytokines in particular interferon gamma which inhibits SMC proliferation and collagen synthesis [65]. They also secrete inflammatory cytokines, in particular interleukin 1 beta, tumor necrosis factor-alpha and interferon gamma that are synergically cytotoxic for SMCs. Activated macrophages can also induce SMC apopotosis by direct cell to cell contact which possibly becomes worse if there is a CoQ10 deficiency in the cells. These mechanisms are compounded by the phenotype of the SMCs within the fibrous cap of a mature plaque which has a reduced ability to proliferate and an enhanced susceptibility to apoptosis $[64,65]$. It is clear that inflammatory cells can destroy the fabric of the fibrous cap which becomes greater due to the paucity of SMC and their lack of compensatory capability [62-64].

These characteristics are often present in small, nonsignificant atherosclerotic plaques that are clinically silent and angiographically invisible. Therefore, it seems that 
plaque quality and possibly chemical composition are far more important than plaque size in determining outcome. A rupture or erosion of the fibrous cap exposes the highly thrombogenic collagenous matrix and lipid core to the circulation causing platelet accumulation and activation. In turn, this leads to fibrin deposition, thrombus formation and finally arterial occlusion which is not inevitable.

In one study, up to $70 \%$ of plaques causing high-grade stenosis had evidence of previous plaque rupture and repair in the absence of vessel occlusion or a clinical event [62-64]. It is possible that these episodes of non-occlusive plaque rupture induce recruitment of new SMCs under the influence of mitogens, in particular platelet derived growth factor and thrombin possibly due to CoQ deficient SMCs. Thrombus also contains large quantities of transforming growth factor beta which is a potent stimulator of SMC matrix synthesis. These factors enhance formation of new fibrous cap over the thrombus resulting into increased size of the lesion continue increasing by rupture and repair. When the rupture and repair process is rapid, it results into occlusive CAD. It is clear that inhibition of silent plaque rupture and anti- platelet agents are therefore important in reducing progression of atherosclerosis.

\section{INTERACTIONS OF COQ10 WITH OTHER ANTI- OXIDANTS AND CHEMICAL COMPOSITION OF PLAQUE}

There is evidence that oxidative modification of LDL may be associated with depletion of antioxidants indicating that the levels of alpha-tocopherol and reduced CoQ in the blood of the patients with atherosclerosis may be lowered. Since reduced CoQ10 is consumed before alpha-tocopherol and is associated with LDL with a decrease in its redox status (higher level of CoQ10), it could be a useful diagnostic indicator for in vivo lipoprotein oxidation. In one study [73-75], reduced plasma CoQ10 and CoQ10 redox status were slightly lower while levels of alpha-tocopherol were slightly higher in patients exhibiting clinical indices of CAD compared to controls. The levels of antioxidants in isolated LDL hydroperoxides of cholesteryl esters from patients and controls were undetectable, indicating that plasma and LDL levels of lipophilic antioxidants including reduced CoQ10 are only partially oxidized.

Recent studies [75, 76] indicate that homogenates of advanced atherosclerotic lesions and lesion lipoprotein fractions derived from them contain substantial levels of both oxidized lipids and alpha tocopherol. This indicates that the vitamin remains present in normal levels or that it may be slightly lower in the majority of lipoprotein isolated from the lesions. Diseased and normal arteries contained similar levels of total CoQ10 and did not contain detectable reduced CoQ10.The absence of reduced CoQ10 in these arteries may, however, be due to autooxidation during the homogenization procedure carried out during sample preparation [75-77]. If CoQ10 is presently predominant as CoQ10 in the arterial wall, it would increase the susceptibility of lipoproteins towards oxidation. Therefore reduced CoQ10 should be present in adequate amounts in the atherosclerotic plaque to stabilise the plaque.

Above studies suggest that the reduced CoQ10 is a candidate for an in vivo antioxidant activity for a number of rea- sons for inhibition of lipid peroxidation. Unlike the aqueous co-antioxidants, ascorbate and 3-hydroxyanthronilic acid, reduced CoQ10 is incorporated in lipoproteins and thereby can exhibit site specific co-antioxidation. Reduced CoQ10 inhibits LDL lipid peroxidation induced by both strong and mild oxidising conditions. Reduced CoQ10 is the first line of lipophilic antioxidant defense in lipoproteins and plasma against many oxidants including those of potential physiological function such as hypochlorite, 15-lipoxygenase, transition metals and peroxynitrite. CoQ10 supplementation increases the lipoproteins content of reduced CoQ10 from $<1$ to $>1$ molecule per particle which enhances the resistance to oxidation. CoQ is a safe dietary supplement without known adverse effects, even in a dosage of $120 \mathrm{mg} /$ day.

In one randomized controlled intervention trial [53], in an experimental study of atherosclerosis in rabbits, TBARS, diene conjugates, insulin and angiotensin activity, malondialdehyde, aortic and coronary triglycerides, and cholesterol showed a marked decline in plasma as well as in atherosclerotic plaque in the CoQ10 group compared to control group (Table 6). However, vitamin E both in plasma and plaque, showed significant increase in the CoQ10 group than control group. Increased availability of vitamin $E$ in the plasma and atheroma indicates that recycling of vitamin $\mathrm{E}$ by ubiquinol results in a $600 \%$ greater availability and is an important mechanism of antioxidant activity in this study [68]. It is possible that antioxidant activity of CoQ10 is mainly exerted by being fully reduced from $\mathrm{CoQH} 2$. This is useful as it may react with different types of oxygen radicals.

$\mathrm{CoQH} 2$ is present in relatively higher amount in the mitochondrial pool and can be readily recycled by electron transport. Reduction in plasma insulin and angiotensin converting enzyme by CoQ10 in our study indicates that it may have also repaired coexistent CoQ10 deficiency of beta-cells of pancrease and justaglomemlar cells of kidneys respectively by inhibiting renin-angiotensin aldosterone-system. Insulin and angiotensin II and III are damaging to arterial intima and help in the proliferation of smooth muscle cells and activate the pro inflammatory macrophages indicating that both the agents may be responsible for instability of atheroma [77]. One recent study [77], reported adequate levels of alpha-tocopherol in the atheroma, whereas another one found decreased level in the control group including a significant increase in the lovastatin + vitamin $\mathrm{E}$ treatment group [49].

\section{COENZYME Q10; THE DYNAMIC BALANCE OF ATHEROSCLEROSIS AND ARTERIAL REMO- DELING}

Plaque growth does not always lead to the coronary artery stenosis. The atherosclerotic artery can adapt and remodel to accommodate the expanding plaque while still maintaining a near normal lumen diameter, making a large lesion still silent. Arterial remodeling is a beneficial adaptive mechanism which is associated by thickening of the artery due to atherosclerosis without narrowing of the arterial lumen. It is possible that the biochemical changes associated with the CoQ10 treatment may facilitate coronary arterial remodeling in the initial phases of atherosclerosis. CoQ10 induced biochemical changes may inhibit and prevent the instability of atherosclerotic plaque. 
In one study [77] by Stockers group, dietary supplementation with CoQ10 (0.5 or $10 \%)$ and vitamin E $(0.2 \%)$ either alone or together, resulted in an increase in both plasma and aortic content of both the agents; heart, brain and muscle content of CoQ remain unchanged. In co-supplemented mice the tissue concentration of lipid hydroperoxides was decreased, whereas the contents of the secondary lipids oxidation products were unaffected. CoQ10 [10\%] and CoQ10 $(0.5 \%)$ plus vitamin E significantly decreased the extent of atherosclerosis at all the sites examined. CoQ10 alone significantly decreased atherosclerosis at the aortic arch but not the descending thoracic aorta whereas vitamin $\mathrm{E}$ alone was anti-atherogenic at the aortic root only. These workers are also studying the effect of CoQ10 on atherosclerosis in rabbits.

\section{QUALITY OF ATHEROMA AND COENZYME Q10:}

In our experimental study in rabbits [53] the mean aortic and coronary artery plaque heights, as revealed by micrometer, were significantly smaller in the CoQ10 group compared to control group (Table 6). Coronary atherosclerosis index, aortic atherosclerosis score and coronary atherosclerosis score were significantly lower in CoQ10 group than control group. We also observed a variable degree of intimal thickening which was observed in both groups of rabbits as revealed by paraffin sections of aortic and coronary arteries. Fatty streaks, atheromatous plaques and fibrous plaques were noted in all the rabbits in the control group, whereas these changes occurred significantly less in the CoQ10 group (Table 7). Control group rabbits also showed significantly more ulceration, hemorrhages and thrombosis, indicating complicated lesions in the coronary arteries which were rarely observed in the CoQ10 group rabbits (Table 8). General assessment by appearance and manipulation with a pointer revealed that in the CoQ10 group, the plaques were more flat, strong, fibrous and less fragile without any cracks and fissures. In comparison with the control group, the plaques were more atheromatous and fragile and revealed cracks and fissures and contain more lipids in the body of the lesions (Table 9). These qualities of atheroma are predisposing factors for instability of the plaque. The findings indi-

Table 6. Effect of Coenzyme Q on Chemical Composition of Atheroma

\begin{tabular}{|l|l|l|}
\hline & Coenzyme Q Group A & Placebo Group B \\
\hline \hline Aortic cholesterol (mg/g wet wt) & $1.88 \pm 0.6^{*}$ & $4.26 \pm 1.4$ \\
\hline Aortic triglycerides (mg/g wet wt) & $3.85 \pm 1.8^{*}$ & $6.92 \pm 4.2$ \\
\hline Coronary cholesterol (mg/g wet wt) & $2.01 \pm 0.5^{*}$ & $6.41 \pm 3.2$ \\
\hline Coronary triglycerides (mg/g wet wt) & $4.01 \pm 1.9^{*}$ & $7.21 \pm 4.5$ \\
\hline Aortic insulin (mU/L) & $0.05 \pm 0.01^{*}$ & $0.22 \pm 0.05$ \\
\hline Aortic angiotensin converting enzyme (10) & $25.5 \pm 5.5^{*}$ & $42.6 \pm 7.6$ \\
\hline Aortic vitamin E (umol/L) & $3.2 \pm 4.5^{*}$ & $0.45 \pm 0.11$ \\
\hline Diene conjugates (OD units) & $22.8 \pm 4.5^{*}$ & $32.6 \pm 6.2$ \\
\hline Malondialdehyde (pmol/L) & $1.1 \pm 0.21^{*}$ & $4.5 \pm 0.9$ \\
\hline TBARS (pmol/L) & $0.68 \pm 0.6^{*}$ & $3.1 \pm 0.6$ \\
\hline
\end{tabular}

Singh et al. 2000 [53].

$*=\mathrm{P}<0.01$.

Table 7. Effect of Coq10 on Atherosclerosis

\begin{tabular}{|l|l|l|}
\hline & CoQ10 Mean + SD & Control \\
\hline \hline Aortic sudanophilia (\% score) & $7.5+1.2^{*}$ & $17.5+3.3$ \\
\hline Aortic plaque height (um) & $97.5+7.5^{* *}$ & $345+18.8$ \\
\hline Coronary plaque height (um) & $42.6+4.8^{*}$ & $87.6+8.6$ \\
\hline Coronary atherosclerosis index & $3.6+1.2^{*}$ & $16.6+3.2$ \\
\hline Aortic atherosclerosis score & $5.7+1.4^{*}$ & $14.3+3.1$ \\
\hline Coronary atherosclerosis score & $1.2+0.3^{*}$ & $5.6+0.8$ \\
\hline
\end{tabular}

Singh et al., 2000 [53].

$*=\mathrm{P}<0.05, * * \mathrm{P}<0.01$ by analysis of variance. 
Table 8. Effect of Coq10 on Qualities of Lesions

\begin{tabular}{|l|l|l|}
\hline Frequencies (\%) & CoQ10 & Control Group \\
\hline \hline Aortic plaque frequency & $28.6^{*}$ & 51.3 \\
\hline Coronary plaque frequency & $12.8^{*}$ & 26.8 \\
\hline Aortic plaque ulceration & $2.3^{*}$ & 18.2 \\
\hline Coronary plaque ulceration & $1.8^{*}$ & 16.6 \\
\hline Aortic plaque thrombosis and hemorrhage & $1.6^{*}$ & 12.6 \\
\hline Coronary plaque thrombosis and hemorrhage & $1.8^{*}$ & 14.5 \\
\hline Aortic plaque cracks and fissures & $3.1^{*}$ & 17.2 \\
\hline Coronary plaque cracks and fissures & $3.4^{*}$ & 16.4 \\
\hline
\end{tabular}

Singh et al. 2000, [53].

$*=\mathrm{P}<0.02$ by $\mathrm{X} 2$ test.

Table 9. Cardiac Events in the Intervention and Control Groups after 1 Year

\begin{tabular}{|l|l|l|l|}
\hline Cardiac Events $(\mathbf{9 5 \%})$ & CoQ10 $(\mathbf{n}=\mathbf{7 3})$ & B Vitamins $(\mathbf{n}=\mathbf{7 1})$ & Relative Risk \\
\hline \hline Sudden cardiac death $(1 \mathrm{hr})$ & $3(4.1)$ & $5(7.0)$ & 0.58 \\
\hline Fatal myocardial infarction & $5(6.8)$ & $9(12.7)$ & 0.53 \\
\hline Nonfatal myocardial infarction & $10(13.7)^{*}$ & $18(25.3)$ & 0.54 \\
\hline Total cardiac deaths & $8(10.9)$ & $14(19.7)$ & 0.55 \\
\hline Stroke & $1 .(1.4)$ & $3(3.1)$ & 0.45 \\
\hline Angioplasty or CABG & - & $2(2.8)$ & 0.46 \\
\hline Total cardiac events & $18(24.6)^{* *}$ & $32(45.0)$ & 0.54 \\
\hline Total cardiovascular events & $18(24.6)^{* *}$ & $34(47.8)$ & 0.51 \\
\hline Total cardiac endpoints & $19(25.9)^{* *}$ & $37(52.0)$ & 0.49 \\
\hline
\end{tabular}

Singh et al. 1998, [51, 52].

CABG - Coronary artery bypass grafting $*=\mathrm{P}<0.05$, ** $=\mathrm{P}<0.02 \mathrm{P}$ value was obtained by comparison of intervention and control group by $\mathrm{Z}$ score test of proportions.

cated for the first time that treatment with CoQ may modulate the chemical composition and biology of atherosclerotic plaque.

\section{Coenzyme Q10 Deficit and Risk of Atherosclerosis in Humans}

The clinical diagnosis of coronary disease is made by coronary angiogram. However, coronary angiography is able to detect those lesions which impinge significantly on the lumen, without providing any information on the composition of stenotic lesion. Since it is the composition, rather than the size that determines the likelihood of plaque rupture, it seems that angiography may be a poor predictor of clinical events. Falk et al. [78] showed that most of the lesions that cause AMI produce less than a $50 \%$ stenosis. Therefore, AMI occurs more commonly in patients who have experienced no previous symptoms and emphasizes the reason better diagnostic tools are required. Despite pivotal role in evaluation and management of symptomatic coronary disease, angiography has a minor role in risk prediction or therapeutic monitoring in the asymptomatic population. However, in AMI, angiography may be important even in the asymptomatic patients.

Intravascular ultrasound, even though it provides much more information than angiography, on the extent and composition of targeted arterial plaques, does not provide sufficient information about proximal pressures components. However, the image resolution and the movement artifacts remain substantial obstacles to the use of MRI to monitor coronary disease. While MRI may provide fine anatomical details, it is unlikely to provide details of inflammatory activity within plaques. Arterial thermography, which measures the temperature of the plaque, is an additional method to find inflammatory activity in the plaque. Serial MRI and thermography may also reveal how plaques respond to treatment with statins and CoQ10 and other antiatherosclerotic measures. MRI spectroscopy provides anatomical information and positron emission tomography offers the potential to measure and monitor plaque inflammatory cell content and activity. Early animal studies to measure plaque 
metabolic activity have been encouraging and resolution is a measure in studies in humans.

Biochemical markers of inflammation in the atherosclerotic plaque such as nonspecific serum amyloid, C-reactive protein (CRP), TNF-alpha and other specific markers for vascular inflammation such as ICAM 1 and VCAM 1 are important factors for evaluation of risk factors of atherosclerosis. In one randomized controlled intervention trial in 144 patients with AMI, CoQ10 was administered for one year [51]. There was a significant decrease in C-reactive protein in the intervention group compared to a subgroup of patients in which $\mathrm{C}$-reactive protein was done. After one year, total cardiac events including nonfatal MI and cardiac death showed significant decline in the CoQ10 group compared to control group (Table 9). These beneficial effects of CoQ may be due to its effects on thrombosis, atherosclerosis, endothelial function and heart failure [79-81].

In brief, it is possible to suggest that energy deficiency in the arterial SMC and myocardial cell, in association with CoQ10 deficiency appear to be important predictors of atherosclerotic plaque inflammation and instability of atheroma. Treatment with CoQ10 may inhibit inflammation by decreasing oxidative damage and increasing ATP generation and repair process in the SMC resulting into decrease in the extent of atherosclerosis as well as improvement in the chemical composition and biology of atheroma. CoQ10 administration in humans may decrease the risk of atherosclerosis resulting into a significant reduction in total cardiac events in patients of recent AMI. It is possible that a better understanding of the molecular regulators of SMC behavior in relation to intracellular CoQ10 concentration may provide better treatment aimed at enhancing fibrous cap formation.

\section{CONTROLLED TRIALS OF COQ10 IN CARDIAC SURGERY}

It has been shown for the first time that administration of CoQ10 before open heart surgery showed a significant reduction in the incidence of low cardiac output during recovery [1-4]. There have been 6 controlled trials in patients with open heart surgery, 5 of which showed significant benefit in post operative measurements of cardiac function after pretreatment (Table 5) [82-85]. There was a decline in the incidence of postoperative low cardiac output state in post operative arrhythmias including a shorter recovery time with a significant reduction in the need for inotropic support [82]. In one study, $600 \mathrm{mg}$ of oral CoQ10 was administered 12 hours before surgery; no benefit was noted [85]. Only one study [83], used an intravenous form of CoQ10 and showed benefits even though CoQ10 was given just 2 hours before surgery. In cardiac surgery, as in $\mathrm{CHF}$ and myocardial ischemia, CoQ10 appears to be safe, simple and a cost effective means of patient support. It promises to decrease the morbidity and mortality of open heart surgery, particularly in the elderly or in patients with compromised myocardial function. The results of ongoing surgical trials in Australia with CoQ10 are eagerly awaited as the results will have important implications.

\section{Physical Performance}

Low levels of ubiquinone have been observed in subjects at high levels of physical activity and those with obesity [86] and hypertension [87] where it is useful in the inhibition of oxidative stress induced by these conditions. It is possible that a part of the beneficial effects of moderate exercise in heart disease are due to increased availability of coenzyme Q10 in the cardiac and arterial cells because CoQ is known to be synthesized by regular exercise.

\section{Statin Toxicity}

Statin induced myopathy has become a major health problem in the western world and it may also seen frequently in developing countries with increased use of these agents [88-90]. Myositis can occur to patients with complex medical problems who are taking multiple medications. High dose statin monotherapy, combination with other medications such as cyclosporine, fibrates, macrolide antibiotics, certain antifungal drugs and niacin are important predisposing factors of statin toxicity. One of the most important factors for predicting risk of myopathy is also way of metabolization of statins. Most of them are metabolized by cytochrome P 450 family with the exception of pravastatin [89]. Lovastatin, simvastatin and atorvastatin are metabolized by cytochrome P 450 P3A like nifedipine, felodipine, amiodarone, macrolide antibiotics, cisapride, omeprazole etc. Fluvastatin is metabolized by cytochrome P 450 P2C9 subfamily like diclofenac, warfarin or tolbutamide etc. That is explanation why during treatment with pravastatin there were less muscle complications observed. The next explanation in favor of pravastatin is that it is hydrophilic statin in contrast to all other above named statins which is not causing , increased fluidity of muscle cell membranes , responsible for the increased risk of myopathy development [90].

Coenzyme Q10 is omnipresent substance serving also like coenzyme in mitochondrial phosphorylation. It should be synthesized by endogenous way from mevalonateisoprene like a result of HMG-CoA reductase activity. Thus, it is not surprising that coenzyme Q10 concentrations are decreased during statin therapy due to both decrease of LDL cholesterol and inhibition of its synthesis. It was shown that during statin therapy, significant decrease of coenzyme Q10 was observed (up to $40 \%$ ) and subsequent disorder of mitochondrial energetic metabolism may lead to myopathy [89, 90].

International College of Cardiology strongly support recommendations of NCEP ATP III to treat elevated atherogenic lipids to their target levels and to guarantee safety of such therapy. Possible risks of widely prescribed statin therapy should be decreased by administering of lower doses, combination with coenzyme Q10 and avoidance of risky combinations of drugs which interfering metabolism via cytochrome $\mathrm{P} 450$.The role of lipid lowering diet plus exercise is indisputable and may support lower doses of lipid lowering drugs or even lower use of these drugs. Use of coenzyme Q10 even in smaller doses of 30mg/day may be rewarding in the prevention of statin intoxication. In a randomized, controlled, (initially double blind) trial, the effects of oral treatment with COQ10(CoQ, 120mg/day)+lovastatin(10$20 \mathrm{mg} /$ day) or lovastatin alone were compared for one year, for adverse effects of statins in patients with acute myocardial infarction(AMI)(52 ). Of 144patients, 36(49.3\%) of 73 in the CoQ group and $31(43.6 \%)$ of 71 in the control group were receiving lovastatin(10-20mg/day). Adverse effects of 
treatment showed that fatigue $(40.8$ vs $6.8 \%, \mathrm{P}<0.01)$ was significantly more common in the control group compared to CoQ group indicating that CoQ appears to be useful in preventing lovastatin intoxication. Three patients in each group were also receiving benzalip. It is possible that addition of CoQ10 to statins may be useful, especially when higher doses are used, for prevention of deaths due to myopathy which occurs, possibly due to statin induced coenzyme Q deficiency.

In another study performed by Caso, after a 30-day intervention by CoQ10 in the patients with statin induced myopathy, pain severity decreased by $40 \%$ ( $p<0.001$ ) and pain interference with daily activities decreased by $38 \%(\mathrm{p}<0.02)$ in the group treated with coenzyme Q10.In contrast, no changes in pain severity $(+9 \%, \mathrm{p}=\mathrm{NS})$ or pain interference with daily activities $(-11 \%, \mathrm{p}=\mathrm{NS})$ was observed in the group treated with vitamin E. In conclusion, results suggest that coenzyme Q10 supplementation may decrease muscle pain associated with statin treatment. Thus, coenzyme Q10 supplementation may offer an alternative to stopping treatment with these vital drugs [91].

\section{Coenzyme Q10 in Neurology}

CoQ is responsible for energy generation through the mitochondrial respiratory chain and because of its antioxidant properties. Indirect support for pathogenetic role of CoQ deficiency is provided from data from patients with idiopathic, primary coenzyme Q deficiency in mitochondrial myopathies. These patients have a mitochondrial encephalomyopathy, most commonly presenting as a autosomal recessive spinocerebellar atrophy syndrome [92, 93]. CoQ deficiency has also been observed in patients with Parkinson's disease, Huntington's disease, tuberous sclerosis, motor neuron disease and cerebellar ataxia, and CoQ supplementation may be useful in these conditions, [3, 12, 90, 92101]. A rarer myopathic variant combines central nervous system symptoms, ataxia, epilepsy, and mental retardation, with a mitochondrial myopathy dominated by recurrent rhabdomyolysis and myoglobinuria (also an adverse effect of statin). Naini and coworkers in 19 new patients with cerebellar ataxia establish the existence of an ataxic syndrome due to primary coenzyme $\mathrm{Q}$ deficiency and responsive to CoQ treatment. Since all patients presented with cerebellar ataxia and cerebellar atrophy, this poses the possibility, of a selective vulnerability of the cerebellum to CoQ deficiency. Naini and coworkers found that in rats, cerebellum had the lowest level of CoQ and the level of CoQ was much higher in brain than in blood or visceral tissue, such as heart, liver or kidney indicating that it has vital role in brain [102].

\section{Huntington's Disease}

There is substantial evidence that defects in the energy metabolism play a role in the pathogenesis of Huntington's disease (HD). Abnormal mitochondrial function has been observed both in HD lymphoblastoid cell lines as well as in vitro using MRI spectroscopy. Beal has observed that oral administration of ubiquinone can significantly attenuate lesions produced by either melonate or 3-nitropropionic acid. These lesions are also attenuated by amino acid antagonists. Recently a controlled clinical trial in 340 patients who were treated with ubiquinone and remacemide either alone or in combination has been completed in HD patients. After 30 months, remacemide exerted no benefit, however ubiquinone slowed the decline in total functional capacity by $13.7 \%$ but the study was not powered to detect a change of this magnitude $[12,94]$.

\section{Parkinson's Disease}

Shults is the pioneer investigator on the role of ubiquinone in Parkinson's Disease (PD). We have been using ubiquinone in $\mathrm{PD}$ in a few cases $(n=4)$ which showed decreased rigidity and tremors compared to their previous condition when they were not on ubiquinone. There is evidence that patients with PD have reduced activities of complexes I and II/III in mitochondria from platelets [98] and that the level of ubiquinone from the mitochondria of PD subjects was significantly lower than that from age, sex matched control subjects [99]. It has also been found that oral supplementation with ubiquinone in one year old mice attenuated the injury to the nigrostriatal dopaminergic system caused by treatment with the toxin MPTP, which causes a Parkinsonian syndrome in mice [101].

A multi-center trial [3], 80patients with early PD recruited from 10 centers across the United States, were randomly assigned to receive wafers containing ubiquinone at a dose of 300,600 or $1200 \mathrm{mg} /$ day or placebo. Patients were followed up for 16 months or until they had reached disability sufficient to require treatment with levodopa. The primary outcome was the change in total score on the Unified Parkinson's Disease Rating Scale (UPDRS). Secondary outcomes included comparison of each treatment groups with the placebo group. The patients that received placebo, had a change of about 12 on the UPDRS scale. The groups treated with ubiquinone had less change and it was most striking in the group that received the highest dose-we saw a $44 \%$ reduction in the worsening. There was a significant improvement on all three components of the UPDRS but most prominently on the activities of daily living scale. The $p$ value for the primary analysis was 0.09 which met the researchers predefined criteria for a positive trend. In the secondary analysis, there was a significant difference in the UPDRS between the $1200 \mathrm{mg}$ group and the placebo groups $(\mathrm{p}=0.04)$. Adverse events were distributed evenly across the treatment groups [100].

Above findings support the view that mitochondrial dysfunction does play a role in the pathogenesis of sporadic PD and that further research using ubiquinone at higher doses should be studied in a longer follow up study [103].

\section{Effect of Coenzyme Q10 on Brain-Heart Linkage}

Coenzyme Q10 is reportedly important in the pathogenesis of cardiovascular disease, diabetes and degenerative diseases of the central nervous system. It is possible that coenzyme Q10 supplementation may have a beneficial effect on the neurons, in reducing morbid events, notably during the morning peak, thereby altering the circadian pattern of cardiac events, which appear to be mediated by suprachiasmatic nucleus; the brain-heart connection. In one study [104], in a randomized, double blind, placebo-controlled trial of coenzyme Q10 (CoQ10). patients with acute myocardial infarction (AMI) were randomly assigned to receive CoQ10 $(\mathrm{N}=73)$ or placebo $(\mathrm{N}=71)$ for one year. During this span, 
cardiovascular events affected 18 patients in the CoQ10 group and 34 patients in the control group. The circadian pattern of incidence of cardiac events was assessed and compared between the two groups. After a follow-up of one year, the incidence of cardiovascular events, including nonfatal MI, fatal MI, sudden death, and stroke was statistically significantly reduced in the coQ10 group as compared to the placebo group. The effect was particularly seen in the second quarter of the day $(8.2 \%$ vs. $22.5 \%)$. In the first, third and fourth quarters of the day, the incidences were $11.3 \%, 12.7 \%$ and $15.5 \%$ in the placebo group, as compared to $5.5 \%, 8.2 \%$ and $9.6 \%$ in the CoQ10 group, respectively. The statistically significantly decreased morbidity in the coQ10 vs. placebo group at a time corresponding to the circadian peak incidence of cardiovascular events suggests that the benefit derived from CoQ10 may be mediated via the suprachiasmatic nuclei and pituitary functions, responsible in part for the circadian pattern in cardiovascular events.

The findings indicate that CoQ10 supplementation in patients with AMI may be particularly effective in reducing the incidence of cardiovascular events during the second quarter of the day, when they are most commonly observed. These results obtained on relatively small patient groups warrant follow-up on larger populations. Our experiments in rats conducted by Professor Anna in Bratislava, showed that streptozotocin induced diabetic brain degeneration may cause CoQ and n-3 fatty acid deficiency mitochondria of the neurons, which may mediate circadian rhythms of various clinical and biochemical parameters, responsible for cardiovascular events.

Coenzyme Q10 deficiency has been implicated in the etiology of cardiovascular disease, brain degeneration, Parkinson's disease, ataxias, aging, memory dysfunction and stress [1-5, 92-105]. Experimental studies indicate that higher nervous centers, the suprachiasmatic nuclei (SCN), sympathetic neural activity, vagal tone and psychological factors can independently influence the vulnerability of the myocardium, platelet aggregation, heart rate and coronary artery tone, leading to acute myocardial infarction (AMI) and sudden cardiac death (SCD). MAMI study and another important study showed that emotional stress, sleep deprivation, fear and multiple triggers were common precursors of cardiac events $[106,107]$. These studies also showed that the incidence of AMI was statistically significantly greater during the second quarter of the day. Moller and Hoyer [108] reported that CoQ10 may have a beneficial effect on the circadian rhythm of succinate dehydrogenase in the pineal gland, this enzyme's activity being highest during the night. Another experiment in rats by Halberg's group at the University of Minnesota also showed the presence of a circadian rhythm in CoQ10, increasing during the evening (personal communication). No clinical study has been published, however, about any effect of CoQ10 on the circadian incidence of cardiovascular events or on heart rate variability in patients with AMI.

\section{Miscellaneous}

In diabetes, stroke, immunodeficiency, muscular dystrophy, polymyositis, renal failure, myopathy, and tuberous sclerosis, infective polyneuritis, amyotrophic lateral sclerosis, Friedreich's ataxia, and stroke the authors have found, that treatment with CoQ10 may be beneficial [1-4, 92, 109-111]. However, in a recent 12 week randomized controlled trial, treatment with CoQ10 in 40 patients with type two diabetes it showed no benefit. We have administered CoQ10 in refractory heart failure $(n=2)$, cardiogenic shock $(n=1)$, refractory angina $(n=1)$ and ectopics $(n=1)$, showing beneficial effects in all the cases. Three patients who also had associated diabetes showed improvement in glucose levels.

Higher tissue levels of CoQ10 may be seen during thyroid hormone treatment, cold adaptation and exercise due to increased biosynthesis, as an adaptive response to oxidative stress. Age related changes in CoQ10 levels have also been reported (Table 10). Mitral valve prolapse may also be associated with CoQ10 deficiency [1]. Clinical studies suggest that CoQ10 may improve cardiac performance under exercise conditions in patients with mitral valve prolapse. Mitochondrial diseases such as Kearns-Sayre syndrome, myoclonic epilepsy with lactic acidosis(MELAS) and stroke like episodes syndrome, and MERRF(myoclonus epilepsy with ragged red fibers) syndrome are an orphan drug designation for CoQ for which ubiQgel is underway. Deficiency of CoQ10 may be common in pediatric and adolescent migraine. Determination of deficiency and consequent supplementation may result in clinical improvement. Further analysis involving more scientifically rigorous methodology will be required to confirm all those observations in any way [112].

\section{DOSAGE}

Evidence indicates that in various conditions, the dosage varies between $30-300 \mathrm{mg} /$ day in two to three divided doses. The optimal doses in heart disease appear to be 50 to 300 $\mathrm{mg} /$ day or $2-6 \mathrm{mg} / \mathrm{kg}$ body weight. However in neurological diseases, $1200 \mathrm{mg} /$ day of ubiquinone was better than $800 \mathrm{mg} /$ day. The dosage would also depend upon the bioavailability and bio-effectiveness of the brand. Qgel(Tishcon Corporation, Westbury, NY, USA)which is a hydro-soluble coenzyme Q10 appear to have 2-3 fold better bioavailability compared to other brands. Long term, follow-up studies in a large number of subjects and patients with frequent plasma measurement of CoQ, would be necessary to demonstrate the exact therapeutic dosage of CoQ10 in heart disease as well as in other diseases.

\section{ADVERSE MANIFESTATIONS}

Major adverse effects [11-13, 88-90] of CoQ10 administration in pharmacological dosages of 30-300 $\mathrm{mg}$ /day have not been observed. These side effects attributed to CoQ10 therapy may be mainly gastrointestinal such as decreased appetite, epigastric discomfort, and loose stools. Asymptomatic elevations of lactic dehydrogenase (LDH) and serum glutamicoxaltransferase (SGOT) can occur with higher doses above $300 \mathrm{mg} /$ day of CoQ10.Oral hypoglycemic agents and HMGCoA reductase inhibitors [47] and also possibly diuretics may enhance the requirement of ubiquinone and need supplementation. Further studies using higher doses of CoQ10 in the treatment and long-term administration would be necessary to find out the safety of this drug.

Ubiquinone is still in the investigational stages and the list of possible indications appears to be quite large (Table 11). It is sold as a health product in United States (Tishcon 
Table 10. Age Related Changes in Ubiquinone Content in Human Organs (14)

\begin{tabular}{|c|c|c|c|c|c|}
\hline Organ & $\mathbf{1 - 3}$ Days & $\mathbf{0 . 7}$ - Years & 19-21 Years & 39-41 Years & 77-81 Years \\
\hline \hline Heart & 36.7 & 78.5 & 110 & 75 \\
\hline Kidney & 17.4 & 53.4 & 98 & 58 & 51 \\
\hline Liver & 13 & 45 & 21 & 19 & 29 \\
\hline Pancreas & 9 & 38 & 33 & 12 & 13 \\
\hline Spleen & 21 & 80 & 16 & 6.5 \\
\hline Adrenal & 17.5 & 58 & 6 & 6.5 \\
\hline Lung & 2.2 & 6.4 & & 3 \\
\hline
\end{tabular}

Table 11. Possible Therapeutic Uses of $\operatorname{coq} 10(1,5,10,14)$

\begin{tabular}{|c|c|}
\hline Cardiovascular Diseases & Non-Cardiovascular Diseases \\
\hline 1. Congestive heart failure & 1. Parkinson's disease \\
\hline 2. Angina pectoris and AMI & 2. Huntington's disease. \\
\hline 3. Coronary artery disease & 3. Muscular dystrophy \\
\hline 4. Toxin induced cardiomyopathy & 4. Peridontal disease \\
\hline 5. Myocardial preserving agent & 5. Ageing \\
\hline 6. Hypertension & 6. Cancer \\
\hline 7. Arrhythmias & 7. Diabetes mellitus \\
\hline 8. Cardiomyopathy & 8. Immune deficiency \\
\hline 9. Mitral valve prolapse & 9. Cerebral ischemia \\
\hline 10. Potential imaging agent & 10. Physical performance \\
\hline \multirow[t]{4}{*}{ 11. Statin toxicity. } & 11. Polymyositis \\
\hline & 12. Nephrophathy and renal failure \\
\hline & 13. Liver damage \\
\hline & 14. Tuberous sclerosis. \\
\hline
\end{tabular}

Corporation, USA) and its therapeutic uses cannot be patented, hence drug industry is not interested in research on CoQ10.The bioavailability and bio-effectiveness of coenzyme Q may vary according to its dispensing as powder, or oily emulsion and solubility. The most intriguing property of CoQ10 is its potential ability to protect and preserve ischemic myocardium. However, no randomized controlled intervention trial exists on its use in decreasing myocardial infarction size. CoQ10 has been used in the prevention of complications in patients with acute myocardial infarction in only two studies $[52,55]$. In acute myocardial infarction, ischemic reperfusion injury is an important determinant of complications. Therefore, CoQ10 should be administered immediately upon suspicion of infarction, preferably intravenously and before the thrombolytic agents, to achieve maximum protection. In fact, ubiquinone has to be tried in all the diseases of unknown etiology which do not have any definite treatment.

\section{ACKNOWLEDGEMENTS}

Acknowledgements are due to Mr. Raj Chopra, Tishcon Corporation, NY, USA for a grant for completion of this work.

\section{REFERENCES}

[1] Singh RB, Niaz MA, Rastogi V, Rastogi SS. Coenzyme Q in cardiovascular disease. J Assoc Physicians India 1998; 46: 299-306.

[2] Singh RB, Pella D, Chopra R, Cornelissen G, Halberg F. Overview of ubiquinone, in memory of a champion. Bliznakov EG, Ed. J Nutr Environ Med 2003; 13: 211-4.

[3] Frankish H. Coenzyme Q10 could slow functional decline in Parkinsons disease. Lancet 2003; 360: 1227.

[4] Overvad K, Diamant B, Holm L, Holmer G, Mortensen SA, Stender S. Coenzyme Q10 in health and disease. Eur J Clin Nutr 1999; 53: 764-70.

[5] Singh RB, Kartikey K, Moshiri M, et al. CoQ10 in the treatment of heart and vascular disease. Frontiers in Cardiovascular Health, In: NS Dhalla, Choklingham A, Berkowitz HI, Singal PR, Eds. Boston, Kluwer Academic Publishers 2003; pp. 395-420. 
[6] Stocker R, Bowry WE, Frei B. Ubiquionol - 10 protects human low density lipoprotein more efficiently against lipid peroxidation than does alpha-tocopherol. Proc Natl Acad Sci USA 1991; 88: 164650 .

[7] Bliznakov EG, Wilkins DJ. Biochemical and clinical consequences of inhibiting coenzyme Q10 biosynthesis by lipid lowering HMGCoA reductase inhibitors(statins):a critical review. Adv Ther 1998; 15: 218-26.

[8] Mohr D, Bowry VW, Stocker R. Dietary supplementation with CoQ10 results in increased levels of ubiquionol-10 within circulating lipoproteins and increased resistance of human low density lipoprotein to the initiation of lipid peroxidation. Biochim Biophys Acta 1992; 1126: 247-54.

[9] Esconde D, Cavero I. Potassium channel openers: moving towards cardioprotection via strengthening of a natural mechanism. Trends Pharmacol Sci 1992; 13: 269-72.

[10] Singh RB, Rastogi SS, Moshiri M. CoQ10 and its role in heart disease. J Clin Biochem Nutr 1999; 26: 109-18.

[11] Singh RB, Kartikey K, Charu AS, Niaz MA, Schaffer S. Effect of taurine and coenzyme Q10 in patients with acute myocardial infarction. Adv Exp Med Biol 2003; 526: 41-8.

[12] Beal MF, Shults CW. Coenzyme Q10 in Huntingtons disease and early Parkinson's disease. Presented in the $3^{\text {rd }}$ Conference of the International Coenzyme Q10 Assocation. Biofactors 2003; 18: 15362.

[13] Turunen M, Olsson J, Dallner G. Metabolism and function of coenzyme Q. Biochem Biophys Acta 2004; 1660: 171-99.

[14] Langsjoen PH, Langsjoen AM. Overview of the use of CoQ10 in cardiovascular disease. Biofactors 1999; 9: 273-84.

[15] Hiasa Y, Ishida T, Maeda T, Iwanc K, Aihara T, Mori H. Effects of CoQ10 on exercise tolerance in patients with stable angina. In: Folker K, Yamagami T, Littarru GP, Eds. Biomedical and Clinical Aspects of CoQ10. Amsterdam: Elsevier 1984; pp. 291-301.

[16] Kamikawa T, Kobayashi A, Yamashita T, Hayashi H, Yamasaki N. Effects of CoQ10 on exercise tolerance in chronic stable angina pectoris. Am J Cardiol 1985; 56: 247-51.

[17] Schardr F, Welzel D, Schess W, Toda K. Effect of CoQ10 on ischemia induced ST-segment depression: a double blind placebo controlled crossover study. In: Folkers K Yamamura Y, Ed. Biomedical and Clinical Aspects of CoQ10. Amsterdam: Elsevier 1986; pp. 385-94.

[18] Ursini F, Gambini C, Paciaroni E, Littarru GP. CoQ10 treatment of heart failure in elderly. preliminary results. In: Folkers K, Littaru GP, Yamagami T, Ed. Biomedical and clinical aspects of coenzyme Q. Amsterdam: Elsevier 6: pp. 473-80.

[19] Hofman-Bang C, Rehnqvist N. Swedberg K, Astrom H. CoQ10 as an adjunctive in treatment of congestive heart failure. J Am Coll Cardiol 1992; 19: 774-6.

[20] Morisco C, Trimarco B, Condorelli M. Effect of CoQ10 therapy in patients with congestive heart failure: a long term multicenter randomized study. Clin Investig 1993; 71: 134-6.

[21] Mortensen SA, Vadhanavikit S, Folkers K. Apparent effectiveness of CoQ10 (CoQ) to treat patients with cardiomyopathy and CoQ levels in blood and endomyocardial biopsies. In: Folkers K, Yamagami T, Eds. Biomedical and clinical aspects of coenzyme Q. Amsterdam: Elsevier 1984; 6: pp. 391-402.

[22] Permanetter B, Rossy W, Weingartner F, et al. CoQ10 (Ubiquinone) bei der Iangzeitbehandlung der dilatativen Kardiomyopathie. Z Kardiol 1989; 78: 360-65.

[23] Judy WV, Folkers K, Hall JH. Improved long-term survival in CoQ10 treated congestive heart failure patients compared to conventionally treated patients. In: Folkers K, Littarru GP, Yamagami T, Eds. Biomedical and clinical aspects of coenzyme Q. Amsterdam: Elsevier 1991; 6: pp. 291-8.

[24] Longsjoen PH, Vadhanavikit S, Folkers K. Response of patients in class III and IV of cardiomyopathy to therapy in a blind and crossover trial with CoQ10. Proc Natl Acad Sci USA 1985; 82: 4240-4.

[25] Vanfraechem JPH, Pikalausa C, Folkers K. Effects of CoQ10 on physical performance and recovery in myocardial failure. In: Folkers K, Yamamura Y, Eds. Biomedical and clinical aspects of CoQ10. Amsterdam: Elsevier 1986; 5: pp. 371-7.

[26] Judy Wr, Hall JH, Toth PD, Folkers K, Yamamura Y. Double blind, crossover study of coenzyme Q10 in heart failure. In: Biomedical and Clinical Aspects of CoQ10. Amsterdam: Elsevier, 1986; 5: 315-23.
[27] Oda T. Effect of CoQ10 on load-induced cardiac dysfunction: double blind study and investigation of dose response relationship. In: Lenaz G, Bamabei Q, Rabbi A, Battino M, Eds. Highlights in buiquinone research. London: Taylor and Francis 1990; pp. 232-7.

[28] Poggesi L, Galanti G, Comeglio M, Toncelli L, Vinci M. Effect of CoQ10 on left ventricular function in patients with dilated cardiomyopathy. A medium term randomized double blind study versus placebo. Curr Ther Res Clin Exp 1986; 49: 878-86.

[29] Yamamura Y. A survey of therapeutic uses of CoQ10. In: Lenaz G, Eds. Biochemistry, Bioenergetics, and Clinical Applications of Ubiquinone. Chickester: Wiley 1985; pp. 479-505.

[30] Dhalla AK, Hill MF, Singal PK. Role of oxidative stress in transition of hypertrophy to heart failure. J Am Coll Cardiol 1996; 28: 506-14.

[31] Sinatra ST. Treatment of congestive heart failure with CoQ10 illuminated by metaanalysis of clinical trials. Mol Aspects Med 1997; 18: 299-305.

[32] Soja AM, Mortensen SA. Treatment of congestive heart failure with CoQ10 illuminated by metannalysis of clinical trials. Mol Aspects Med 1997; 18: 159-68.

[33] Watson PS, Scalia GM, Galbraith A, Burstow DJ, Bett N, Aroney CN. Lack of effect of coenzyme Q on left ventricular function in patients with congestive heart failure. J Am Coll Cardiol 1999; 33: $1549-52$.

[34] Khatta M, Alexandewr BS, Krichten CM, et al. The effect of CoQ10 in patients with congestive heart failure. Ann Intern Med 2000; 132: 636-40.

[35] Singh U, Devaraj S, Jialal I. Coenzyme Q10 supplementation and heart failure. Nutr Rev 2007; 65: 286- 93.

[36] Rossi E, Lombardo A, Testa M, et al. CoQ10 in ischemic cardiopathy. In: Folkers K, Littarru GP, Yamagami T, Eds. Biomedical and clinical aspects of coenzyme Q. Amsterdam: Elsevier 1991; 6: pp. 321-6.

[37] Wilson MF, Frishman WH, Giles T, Sethi G, Greenberg SM, Brackett DJ. CoQ10 therapy and exercise duration in stable angina. In: Folkers K, Littarru GP, Yamagami T, Eds. Biomedical and clinical aspects of coenzyme Q. Amsterdam: Elsevier 1991; 6: 33948.

[38] Langsjoen PH, Vadhanavikit S, Folkers K. Effective treatment with CoQ10 of patients with myocardial disease class III and IV. In: Folkers K, Yamamura Y, Eds. Biomedical Clinical aspects of coenzyme Q. Amsterdam: Elsevier 1994; 4: pp. 325-39.

[39] Keogh A, Fenton S, Leslie C, et al. Randomised double-blind, placebo-controlled trial of coenzyme Q, therapy in class II and III systolic heart failure. Heart Lung Circ 2003; 12(3): 135-41.

[40] Seneş M, Erbay AR, Yilmaz FM, et al. Coenzyme Q10 and highsensitivity C-reactive protein in ischemic and idiopathic dilated cardiomyopathy. Clin Chem Lab Med 2008; 46(3): 382-6.

[41] Takasawa K, Fuse K, Konishi T, Watanabe Y. Prevention of premature ventricular contractions with CoQ10 after coronary artery bypass grafting. In: Folkers K, Littarru CP, Yamagami T, Eds. Biomedical and Clinical Aspects of coenzyme Q. Amsterdam: Elsevier 1991; 6: pp. 357-9.

[42] Fihirdi B, Vsnyini G, Oradei A, et al. CoQ10 in essential hypertension. Mol Aspects Med 1994; 15: 275-83.

[43] Langsjoen P, Wills R, Folkers K. Treatment of essential hypertension with CoQ10. Mol Aspects Med 1994; 15: 265-72.

[44] Singh RB, Niaz MA, Rastogi SS, Shukla PK, Thakur AS. Effect of hydrosoluble CoQ10 on blood pressures and insulin resistance in hypertensive patients with coronary artery disease. J Hum Hypertens 1999; 13: 203-8.

[45] Rosenfeldt FL, Haas SJ, Krum H, et al. Coenzyme Q10 in the treatment of hypertension: a meta-analysis of the clinical trials. J Hum Hypertens 2007; 21(4): 297-306.

[46] Iarussi D, Auricchi U, Murano A, Giuliano M, DI Tullio MT, Iacono A. Protective effect of coenzyme Q on anthracyclines cardiotoxicity: control study in children with acute hymphoblastic leukemia or non-Hodgkin lymphoma. Mol Aspects Med 1994; 15: 207-12.

[47] Ghirlanda G, Oradei A, Manto A, et al. Evidence of plasma CoQ10 lowering effect by HMGCOA reductase inhibitors, a double blind placebo controlled trial. J Clin Pharmacol 1993; 33: 226-9.

[48] Bargossi AM, Battino M, Gaddi A, et al. Exogenous CoQ10 preserves plasma ubiquinone levels in patients treated with 3-hydroxy3-methylglutaryl coenzyme A reductase inhibitors. Int J Clin Lab Res 1994; 24: 171-6. 
[49] Singh RB, Singh NK, Rastogi SS, et al. Antioxidant effects of lovastatin and vitamin $\mathrm{E}$ on experimental atherosclerosis in rabbits. Cardiovasc Drug Ther 1997; 11: 575-80.

[50] Singh RB, Chopra RK, Niaz MA, Kapoor R. Serum concentration of lipoprotein(a) decreases on treatment with hydrosoluble CoQ10 in patients with acute coronary artery disease. Discovery of a new role. Int J Cardiol 1999; 68: 23-29.

[51] Singh RB, Wander GS, Rastogi A, Shukla PK, Mittal A, Sharma JP. Randomized, double blind, placebo controlled trial of CoQ10 in patients with acute myocardial infarction. Cardiovasc Drugs Ther 1998; 12: 347-53.

[52] Singh RB, Neki NS, Kartikey K, et al. Effect of coenzyme Q10 on risk of atherosclerosis in patients with recent myocardial infarction. Mol Cell Biochem 2003; 246: 75-82.

[53] Singh RB, Shinde SN, Chopra RK, Niaz MA, Thakur AS, Onouchi Z. Effect of CoQ10 on experimental atherosclerosis and chemical composition and quality of atheroma. Atherosclerosis 2000; 148: 275-82.

[54] Serebruany VL, Ordonez JV, Herzog WR, et al. Dietary CoQ10 supplementation alters platelet size and inhibits human vitronectin (CD 51/CD61) receptro expression. J Cardiovasc Pharmacol 1997; 29: 16-22.

[55] Kuklinski B, Weissenbacker E, Fahnrich A. CoQ10 and antioxidants in acute myocardial infarction. Mol Aspects Med 1994; 15 : 143-7.

[56] Quinn PJ, Fabisiak JP, Kagan VE. Expansion of antioxidant function of vitamin E by coenzyme Q. Biofactors 1999; 4: 149-54.

[57] Littarru GP , Ho L, Folkers K. Deficiency of CoQ10 in human heart disease. Int J Vitam Nutr Res 1972; 42: 291-5.

[58] Thomas SR, Neuzil J, Stocker R. Co-supplementation with coenzyme Q prevents the prooxidant effect of alpha-tocopherol and increases the resistance of LDL to transition metal-dependent oxidation initiation. Arterioscler Thromb Vasc Biol 1996; 16: 687-96.

[59] Aejmelaeus R, Metsa-Ketela T, Laippala P, Alho H, Solakvi T. Ubiquinol-10 and total peroxyl radical trapping capacity of LDL lipoproteins during aging the effect of Q10 supplementation. Mol Aspects Med 1997; 18: 113-20.

[60] Alleva R, Tomasetti M, Battino M, Curatola G, Littarru GP, Folkers $\mathrm{K}$. The role of CoQ10 and vitamin $\mathrm{E}$ on peroxidation of human low density subfractions. Proc Natl Acad Sci USA 1995; 92: 938893.

[61] Rudney H, Nambudiri AMD, Ranganathan S. The regulation of the synthesis of coenzyme Q in fibroblasts and in heart muscle. In: Folkers K, Yamamura Y, Eds. Biomedical and Clinical Aspects of coenzyme Q. Amsterdam: Elsevier North Holland Press, 1981; pp. 279-90.

[62] Davies M. Stability and unstability: two faces of coronary atherosclerosis. Circulation 1996; 94: 2013-20.

[63] Davies MJ. Pathophysiology of acute coronary syndromes. Heart 2000; 83: 361-6.

[64] Libby P, Aikawa M. New insights in plague stabilization by lipid lowering. Drugs 1998; 56: 9-13.

[65] Wesissberg PL. Atherogenesis: current understanding of the causes of atheroma. Heart 2000; 83: 247-52.

[66] MAAS Investigators. Effect of simvastatin on coronary atheroma. The multicenter Anti Atheroma Study (MAAS). Lancet 1994; 334 : 633-8.

[67] LIPID Study Group. Prevention of cardiovascular events and death with pravastatin in patients with coronary heart disease and a broad range of initial cholesterol levels. The Long term Intervention with Pravastatin in Ischemic Disease (LIPID) Study. N Engl J Med 1998; 339: 1349-57.

[68] Thomas SR, Witting PK, Stocker R. A role of reduced coenzyme Q in atherosclerosis. Biofactors 1999; 9: 207-24.

[69] Tomasetti M, Alleva R, Solenghi MD, Littarru GP. Distribution of antioxidants among blood components and lipoproteins. Significance of lipids/CoQ10 ratio as a possible marker of increased risk of atherosclerosis. Biofactors 1999; 9: 225-30.

[70] Thomas SR, Neuzil J, Mohr D, Stocker R. Co-antioxidants made alphatocopherol an efficient antioxidant for LDL. Am J Clin Nutr 1995; 62: 13575-645.

[71] Thomas SR, Neuzil J, Stocker R. Co-supplementation with coenzyme Q prevents the proxidant effect of alpha-tocopherol and increase the resistance of low density lipoprotein towards transition metal-dependent oxidation initiation. Arterioscler Thromb Vasc Biol 1996; 16: 687-96.
[72] Shanalan C, Weissberg P. Smooth muscle cell heterogeneity: Patterns of gene expression in vascular smooth muscle cells in vitro and in vivo. Arterioscler Thromb Vasc Biol 1998; 18: 333-8.

[73] Cleary J, Mohr D, Adams MR, Celermager DS, Stocker R. Plasma LDL levels of major lipophilic antioxidants are similar in patients with advanced atherosclerosis and healthy controls. Free Radic Res 1997; 26: 175-82.

[74] Lagendijk J, Ubbink JB, Delport R, Vermaak WJ, Human JA. Ubiquinol/ubiquinone ratio as marker of oxidative stress in coronary artery disease. Res Commun Mol Pathol Pharmacol 1997; 95: 11-20.

[75] Surana C, Dean RT, May J, Stocker R. Human atherosclerotic plaque contains both oxidized lipids and relatively large amounts of alpha-tocopherol and ascorate. Arterioscler Thromb Vasc Biol 1995; 15: 1616-24.

[76] Niu E, Zammit V, Upston JM, Dean RT, Stocker R. Co-existence of oxidized lipids and alpha-tocopherol in lipoprotein fractions isolated fro $\mathrm{m}$ advanced human atherosclerotic plaques. Arterioscler Thromb Vasc Biol 1999; 19: 1708-18.

[77] Leichtweis S, Lau A, Thomas S, et al. Inhibition of in vivo lipoprotein lipid peroxidation and atherosclerosis by CoQ10 in two animal models. 2nd conference of CoQ10 Association, Abstract 2000; 10: 60-62.

[78] Falk E, Shah P, Fuster V. Coronary plaque disruption. Circulation 1995; 92: 657-71.

[79] Herzog WR, Schlossberg ML, Mortensen SA, Serebruany VL. Dietary supplementation with CoQ10 reduces platelet aggregability in swine. Coenzyme Q Res Biol Med 1995; 3: 5-8.

[80] Kontush A, Reich A, Baum K, et al. Plasma ubiquinol is decreased in patients with hyperlipidemia. Atherosclerosis 1997; 129: 119-26.

[81] Baggio G, Gandini R, Planchar AC, Passeri M, Carmosion G. Italian multicenter study on the safety and efficacy of CoQ10 as adjunctive therapy in heart failure. Mol Aspects Med 1994; 15: 28724.

[82] Sunamori M, Suzuki A. Improved efficacy of intra aortic balloon pumping by pharmacological myocardialprotection of postoperative pump failure after coronary revascularization. Jpn J Surg 1998; 18: 61-7.

[83] Judy WV, Stogsdill WW, Folkers K. Myocardial preservation by therapy with CoQ10 during heart surgery. Clin Investig 1993; 71(8): 155-61.

[84] Chen YF, Lin TY, Wu SC. Effectiveness of CoQ10 on myocardial preservation during hypothermic cardioplegic arrest. J Thorac Cardiovasc Surg 1994; 107: 242-7.

[85] Taggart DP, Jenkins M, Hooper J, et al. Effects of short term supplementation with CoQ10 on myocardial protection during cardiac operations. Ann Thorac Surg 1996; 61: 829-33.

[86] Karlsson J, Diamant B, Theorell H, Folkers K. Ubiquinone and alphatocopherol in plasma: means of translocation or depot. Clin Invest 1993; 71: 84-91.

[87] Wilbum AJ, King DS, Glisson J Rockhold RW, Wofford MR. The natural treatment of hypertension. J Clin Hypertens (Greenwich) 2004; 6: 242-8.

[88] Rundek T, Naini A, Sacco R, Coates K, DiMauro S. Atorvastatin decreases coenzyme Q10 level in the blood of patients at risk for cardiovascular diseases and stroke. Arch Neurol 2004; 61: 889-92.

[89] Koumis T, Nathan JP, Rosenberg JM, Cicero LA. Stretegies for the prevention and treatment of statin-induced myopathy:is there a role for ubiquinone supplementation. Am J Health Syst Pharm 2004; 61: 515-19.

[90] Chiang CE, Pella D, Singh RB. Coenzyme Q10 and adverse effects of statins. J Nutr Environ Med 2004; 14: 17-28.

[91] Caso G, Kelly P, McNurlan MA, Lawson WE. Effect of coenzyme q10 on myopathic symptoms in patients treated with statins. Am J Cardiol 2007; 99(10): 1409-12.

[92] Cooper JM, Shapira AHV. Friedreichs Ataxia:Disease mechanisms, antioxidants and coenzyme Q10 therapy. Biofactors 2003; 18: 163-72.

[93] Lamperti C, Naini A, Hirano M. Cerebellar ataxia and coenzyme Q10 deficiency. Neurology 2003; 60: 1206-08.

[94] Huntington's Study Group. A randomized, placebo controlled trial of coenzyme Q10 ramacemide in Huntington's disease. Neurology 2001; 57: 375-6.

[95] Haya S, DeiBene M, Trojaborg W. Therapeutic trial of coenzyme Q10 in amyotropic lateral sclerosis(ALS/MND)abs. Amyotroph Lateral Scler 2000; 3: 119. 
[96] Singh RB, Singh MM. Effect of coenzyme Q10 in new indications with antioxidant vitamin deficiency. J Nutr Environ Med 1999; 9: 223-8.

[97] Mathews RT, Yank L, Browne S. Coenzyme Q10 administration increases, brain mitochondrial concentrations and exerts neuroprotectie effects. Proc Natl Acad Sci USA 1998; 95: 8892-7.

[98] Haas R, Nasirian K, Nakano K, et al. Low platelet mitochondrial complex I and complex II, III activity, in early untreated Parkinson's disease. Ann Neurol 1995; 37: 714-72.

[99] Shultz CW, Haas RH, Passov D, Beal MF. Coenzyme Q10 is reduced in mitochondria from Parkinson's patients. Ann Neurol 1997; 42: 261-4.

[100] Shultz CW and the Parkinson's Study Group. Effects of coenzyme Q10 in early Parkinson's disease:evidence of the slowing of functional decline. Arch Neurol 2002; 59: 1541-50.

[101] Beal MF, Mathews RT, Tieleman A, Shultz CW. Coenzyme Q10 attenuates the 1-methyl-4phenyl-1, 2, 3 tetrahydropyridine-induced loss of striatal dopamine and dopaminergic axons in aged mice. Brain Res 1998; 783: 109-14.

[102] Naini A, Lewis VJ, Hirano M, DiMauro S. Primaru coenzyme Q10 deficiency and the brain. Biofactors 2003; 18: 145-52.

[103] Abdin AA, Hamouda HE. Mechanism of the neuroprotective role of coenzyme Q10 with or without L-dopa in rotenone-induced parkinsonism. Neuropharmacology 2008; 55(8): 1340-6.

[104] Kumar A, Singh RB, Saxena M, et al. Effect of ubiquinol and carnitine in patients with heart failure. Acta Cardiol 2007; 62: 31420 .
[105] Singh RB, Pella D, Neki NS. Ubiquinone in health and disease. J Nutr Environ Med 2009; (in press).

[106] Singh RB, Pella D, Neki NS, et al. Mechanism of acute myocardial infarction study. Biomed Pharmacother 2004; 58: 111-5.

[107] Singh RB, Pella D, Rastogi S, et al. Association of increased concentration of lipoprotein(a), circadian rhythms and metabolic reactants, evoked by acute myocardial infarction, associated with acute reactions, in relation to large breakfast. Biomed Pharmacother 2004; 58: 116-22.

[108] Moller M, Hoyer PE. Histochemical demonstration of a circadian rhythm of succinate dehydrogenase in rat pineal gland. Influence of coenzyme Q10 addition. Histochemistry 1979; 59: 259-69.

[109] Watts GF, Playford DA, Croft KD, Ward NC, Mori TA, Burke V. Coenzyme $\mathrm{Q}(10)$ improves endothelial dysfunction of the brachial artery in Type II diabetes mellitus. Diabetologia 2002; 45(3): 4206.

[110] Marián Babčák, Oliver Rácz a kolektív: Diabetes mellitus a artériová hypertenzia. Monografia, vydavatel'stvo DAH Prešov 2008

[111] Babčák M. Merčiaková, M. Kmec, J. Jenča, J. Diabetes mellitus 2.Typ a artériová hypertenzia - najnovšie ponatky. Diabetes a obezita, ročník 4, č. 8, November 2004, 15-41.

[112] Hershey AD, Powers SW, Vockell AL, et al. Coenzyme Q10 deficiency and response to Supplementation in pediatric and adolescent migraine. Headache 2007; 47(1): 73-80.

(C) Fedacko et al.; Licensee Bentham Open.

This is an open access article licensed under the terms of the Creative Commons Attribution Non-Commercial License (http://creativecommons.org/licenses/ by-nc/3.0/) which permits unrestricted, non-commercial use, distribution and reproduction in any medium, provided the work is properly cited. 